\title{
Echinococcus metacestodes as laboratory models for the screening of drugs against cestodes and trematodes
}

\author{
A. HEMPHILL ${ }^{1 *}$, B. STADELMANN ${ }^{1}$, S. SCHOLL ${ }^{1}$, J. MÜLLER ${ }^{1}$, M. SPILIOTIS ${ }^{1}$, \\ N. MÜLLER ${ }^{1}$, B. GOTTSTEIN ${ }^{1}$ and M. SILES-LUCAS ${ }^{2}$ \\ ${ }^{1}$ Institute of Parasitology, University of Berne, Laenggass-Strasse 122, CH-3012 Berne, Switzerland \\ ${ }^{2}$ Parasitology Laboratory, Instituto de Recursos Naturales y Agrobiología de Salamanca (CSIC), Cordel de Merinas 40-52, \\ 37008 Salamanca, Spain
}

(Received 12 Fune 2009; revised 23 Fuly 2009; accepted 25 Fuly 2009; first published online 21 September 2009)

SUMMAR Y

Among the cestodes, Echinococcus granulosus, Echinococcus multilocularis and Taenia solium represent the most dangerous parasites. Their larval stages cause the diseases cystic echinococcosis (CE), alveolar echincoccosis (AE) and cysticercosis, respectively, which exhibit considerable medical and veterinary health concerns with a profound economic impact. Others caused by other cestodes, such as species of the genera Mesocestoides and Hymenolepis, are relatively rare in humans. In this review, we will focus on $E$. granulosus and $E$. multilocularis metacestode laboratory models and will review the use of these models in the search for novel drugs that could be employed for chemotherapeutic treatment of echinococcosis. Clearly, improved therapeutic drugs are needed for the treatment of AE and CE, and this can only be achieved through the development of medium-to-high throughput screening approaches. The most recent achievements in the in vitro culture and genetic manipulation of E. multilocularis cells and metacestodes, and the accessability of the E. multilocularis genome and EST sequence information, have rendered the E. multilocularis model uniquely suited for studies on drug-efficacy and drug target identification. This could lead to the development of novel compounds for the use in chemotherapy against echinococcosis, and possibly against diseases caused by other cestodes, and potentially also trematodes.

Key words: Cystic echinococcosis (CE), alveolar echinococcosis (AE), Echinoccoccus granulosus, Echinoccoccus multilocularis, in vitro culture, chemotherapy.

\section{INTRODUCTION}

The genus Echinococcus includes seven to nine described species (Nakao et al. 2007; Varcasia et al. 2008). Of these, Echinococcus multilocularis (the small fox tapewom) is the most pathogenic, and E. granulosus (the small dog tapeworm) represents the most common species (Thompson, 1986). Both cause lifethreatening diseases of serious public health and economic concern worldwide (McManus et al. 2003). Alveolar echinococcosis (AE), caused by E. multilocularis, is largely restricted to the Northern hemisphere, such as Central Asia, Russia, Western China, Europe and Japan. Infections with E. granulosus, the causative agent of cystic echinococcosis (CE), occur globally, and mostly in the Mediterranean area, Central Europe, South America, Africa, Central Asia, and CE exists as an imported disease in Western Europe and the USA (Schantz et al. 1995; Eckert and Deplazes, 2004). 3.6 million disabilityadjusted life years (DALYs) are lost due to CE (Craig

* Corresponding author: Andrew Hemphill, Institute of Parasitology Vetsuisse Faculty, University of Berne Länggass-Strasse 122, CH-3012 Berne, Switzerland. Tel: +41316312384. Fax: +41316312477. Email: hemphill@ipa.unibe.ch et al. 2007), showing that the impact of the disease is comparable to onchocercosis and African trypanosomosis (Budke et al. 2006). AE and CE are diseases of communities that often lack essential resources, thus the development of new drugs against these diseases has not been a major focus of the pharmaceutical industry. First, because the population affected and the number of cases as such do not represent a promising market. Secondly, there has been an inherent lack of in vitro culture systems that would allow cost-effective high-throughput drug screening. However, the recent achievements in the establishment of in vitro cultivation systems, especially for E. multilocularis metacestodes, has now opened the door for medium-to-high-throughput drug screening possibilities. These developments could have considerable impact not only for the treatment of echinococcosis, but also for other diseases caused by cestodes such as Taenia, Hymenolepis, Mesocestoides and Spirometra and, potentially, trematodes.

\section{ECHINOCOCCUS: BIOLOGY AND DISEASE}

E. multilocularis and E. granulosus share some distinct features in their life cycle. The adult worms live 


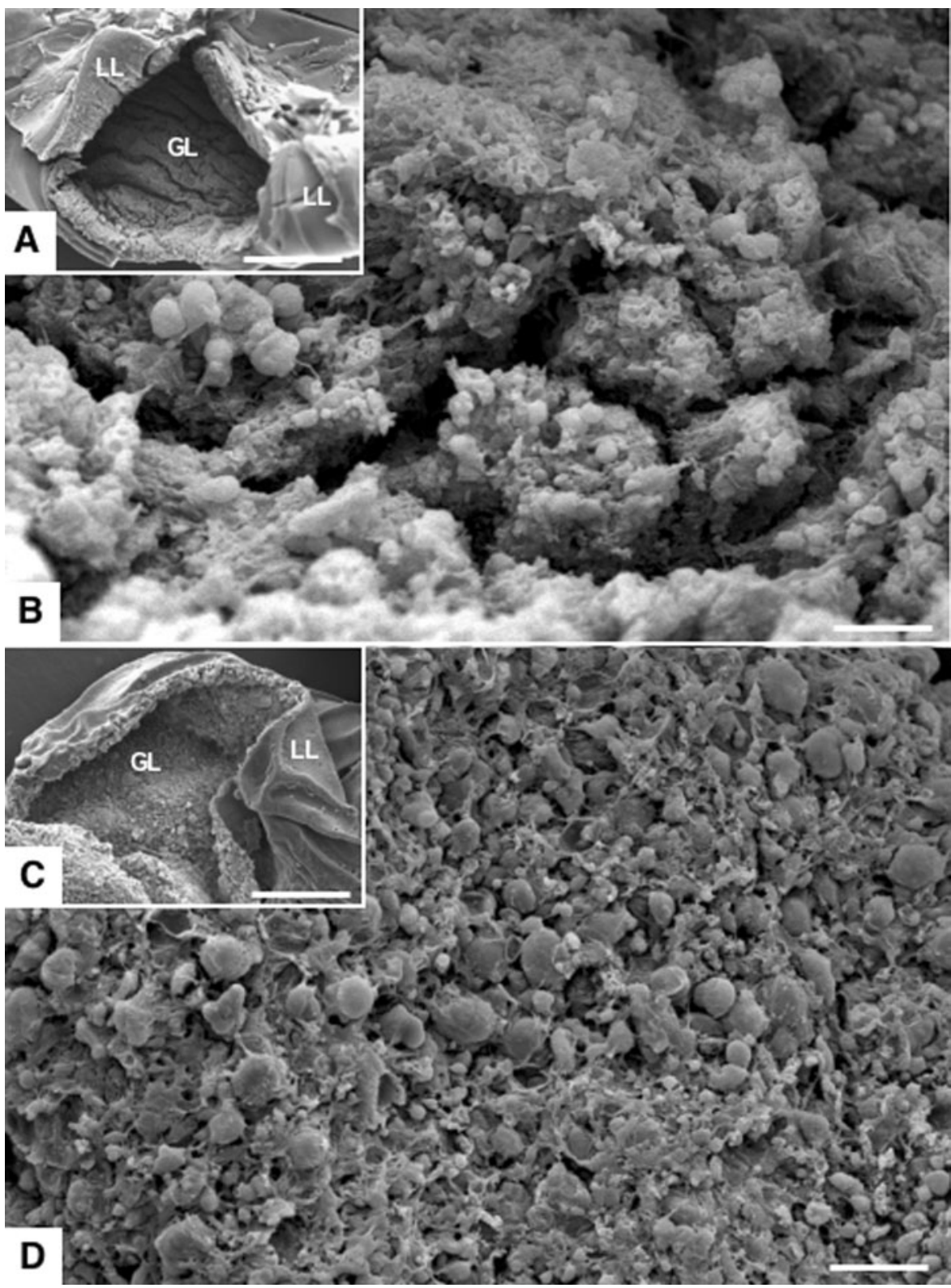

Fig. 1. SEM of E. granulosus (A, B) and E. multilocularis (C, D) metacestodes. A and C represent lower magnification views of broken vesicles, exoposing both the acellular laminated layer (LL) and the germinal layer $(\mathrm{GL})$; bars $=1.5 \mathrm{~mm}$. B and D represent higher magnification views of the germinal layer of E. granulosus and E. multilocularis, respectively; bars $=400 \mu \mathrm{m}$.

in the intestine of their respective final host (dogs for E. granulosus, foxes, dogs and cats for E. multilocularis) where sexual reproduction and subsequent egg production takes place. Faecal shedding spreads the eggs into the environment, where they are accidentally taken up by suitable intermediate hosts, such as small rodents for E. multilocularis, and cattle and sheep for E. granulosus. These eggs contain the first larval stage, the oncosphere, and during stomach passage, the oncosphere is activated and leaves the protective egg. It actively penetrates the intestinal lining, and migrates via blood and lymphatic vessels to the visceral organs. These are primarily the liver for E. multilocularis, and the liver, lung and other target organs in the case of E. granulosus. There, these oncospheres develop into metacestodes, which represent the second larval stage. Within these metacestodes, protoscolex development takes place, and upon oral uptake by the respective final host, protoscoleces attach to the intestinal epithelium and develop into adult worms, thus concluding the life cycle (Rausch, 1995).

Metacestodes of both species are fluid-filled vesicles, and represent the disease-causing stage. They are structured into an inner cellular and an outer acellular compartment (Fig. 1). The outer, acellular surface of the metacestode is formed by the laminated layer, a carbohydrate-rich structure 


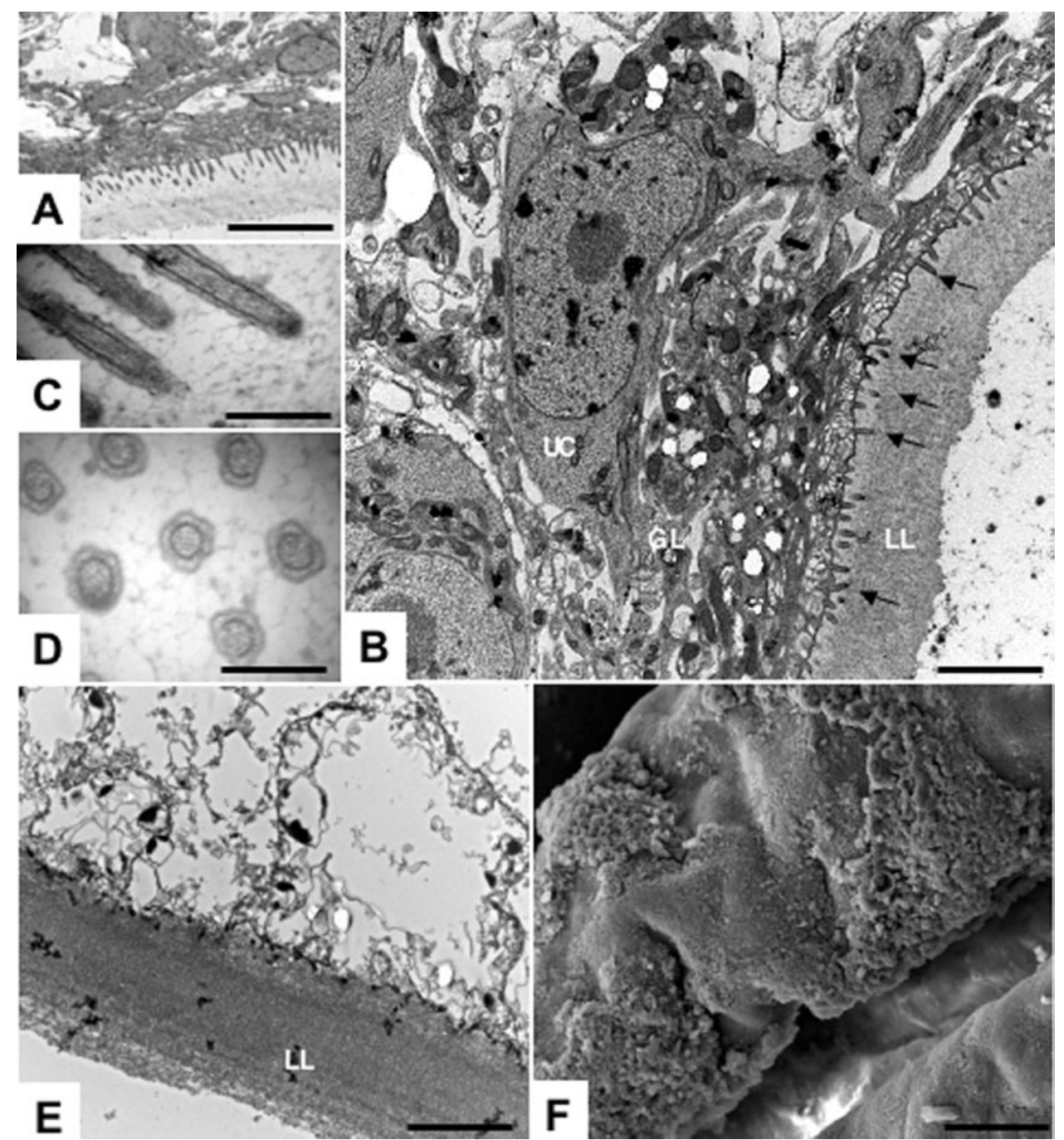

Fig. 2. TEM of E. multilocularis metacestodes cultured in vitro. A shows a low magnification view of a section through the metacestode wall, with laminated (LL) and germinal layer (GL); bar $=7 \mu \mathrm{m}$. B shows a higher magnification view, demonstrating LL, GL-tissue with different cell types including undifferentiated cells with a large nucleus and nucleolus (uc), and the tegument with microtriches (arrows); bar $=3 \cdot 2 \mu \mathrm{m}$. C and D show higher magnification views of longitudinally sectioned $(\mathrm{C}$; bar $=0.56 \mu \mathrm{m})$ and cross-sectioned $(\mathrm{D} ; \mathrm{bar}=0.43 \mu \mathrm{m})$ microtriches revealing actin microfilaments as main structural components. Also note the filamentous meshwork of electron-dense thin filaments that is embedded into the matrix of the LL.

synthesized by the parasite. The laminated layer covers the entire metacestode surface, and is much more prominent in E. granulosus metacestodes (Morseth, 1967; Gottstein and Hemphill, 1997). The actual larval tissue is formed by the germinal layer, which itself is composed of a population of different cell types (Figs. 1 and 2). One part consists of the tegument, which is directly associated with the inner surface of the laminated layer. It is characterized by microvilli-like extensions, microtriches, which protrude into the matrix of the laminated layer and thereby increase the resorbing surface of the parasite (Fig. 2). In addition, the germinal layer contains highly differentiated cell types including connective tissue, muscle cells, and glycogen storage cells, as well as many undifferentiated cells (Fig. 2).
The fully mature E. granulosus metacestode (i.e. hydatid cyst) is a single-chambered or septate unilocular cyst that shows expansive growth and thereby causes compression of neighbouring tissue, tissue damage and organ dysfunction (Kern, 2006). Accidental or traumatic cyst rupture can result in release of cyst fluid and dissemination of protoscoleces, leading to anaphylactic reactions and metastases (secondary echinococcosis) (Stey and Jost, 1993). E. granulosus metacestodes are surrounded by a host fibrous capsule, the adventitial layer, which is composed of host connective tissue.

In E. multilocularis infection, metacestode development exhibits different characteristics. There is no limiting host-tissue barrier comparable to the adventitial layer. The metacestode tissue represents a multivesicular structure that is reproducing 
asexually, by formation and budding of daughter vesicles, with progressive tumour-like growth (AliKhan et al. 1983). This leads to the formation of a large and heterogenous parasitic mass that is intermingled with host connective tissue, proliferative in the periphery, and often necrotic in the centre (Gottstein and Hemphill, 1997). Metastases formation may occur in other organs due to the release of germinal layer cells into the blood or lymph system (Ali-Khan et al. 1983; Eckert et al. 1983; Mehlhorn et al. 1983). Thus, AE can resemble a benign malignant tumour (Vuitton, 2009). Protoscolex development in humans has been rarely observed.

BENZIMIDAZOLES FOR THE

CHEMOTHERAPEUTIC TREATMENT OF CYSTIC

ECHINOCOCCOSIS (CE) AND ALVEOLAR

ECHINOCOCCOSIS (AE)

For many years, the preferred treatment strategy for $\mathrm{CE}$ has been radical resection of the parasite mass (Kern, 2003, 2006). Other options include imageguide percutaneous treatment $(\mathrm{PAIR}=$ puncture, aspiration, injection, reaspiration) (Brunetti et al. 2004) and chemotherapy (El-On, 2002). Both surgery and PAIR are always accompanied by chemotherapy and, for inoperable cases, chemotherapy remains the only option. These cases include patients exhibiting cysts in crucial organs such as spine, pelvis and other sites that are not easily accessible, or patients with multiple cysts in several organs. The currently used drugs are mebendazole and albendazole. These drugs clearly have the potential to kill metacestodes, and to cure the patients. Benzimidazoles exert their action by binding to tubulin, inducing microtubule depolymerization and inhibiting polymerization of this essential cytoskeletal element (reviewed by Hemphill and Müller, 2009). However, the efficacy of these benzimidazoles depends on size and type of cyst (benzimidazoles are more effective against smaller cysts), on the age of the patient (these drugs work better in younger than in older patients), and on which organ is affected (e.g. cysts localized in bones are less susceptible to chemotherapy than those in liver and lungs). The duration of treatment plays a crucial role, with prolonged drug administration producing the most favourable results for the patients (Horton, 1997; Franchi et al. 1999; Vutova et al. 1999). Praziquantel, a heterocyclic pyrazinoisoquinoline derivative, has been proposed to be used alongside benzimidazoles in CE-patients. Praziquantel is well tolerated, less toxic and better absorbed than albendazole. Praziquantel is used against the adult stages of Echinococcus and many other cestodes, and was shown to exhibit a high efficacy against protoscoleces (Morris et al. 1986) and metacestodes in animal experiments (Urrea-Paris et al. 1999, 2001). The mode of action of praziquantel is a matter of debate. Respective studies were mostly carried out with schistosomes, where praziquantel represents the only drug that is currently marketed. Possibilities of praziquantel toxicity include its actions on nucleoside uptake (Angelucci et al. 2007), inhibition of phospho-inositide turnover (Wiest et al. 1992), binding to parasite actin (Tallima and El Ridi, 2007) and the parasite myosin light chain, and possibly inhibiting its functional activity (Gnanasekar et al. 2009), interference in glutathioneS-transferase activity (McTigue et al. 1995), and stimulation of $\mathrm{Ca}^{2+}$ entry through voltage-operated $\mathrm{Ca}^{2+}$ channels (VOCCs) (Kohn et al. 2003; Jeziorski and Greenberg, 2006). The most compelling evidence for the involvement of VOCCs was recently provided by Nogi et al. (2009): they used the freeliving flatworm Dugesia japonicum and investigated regeneration of fragments excised from this planarian that have the ability to reform a complete body plan, an ability that is driven by a totipotent population of stem cells called neoblasts. In the presence of praziquantel, however, this regeneration process yielded complete duplication of the entire antieriorposterior axis, resulting in two-headed organisms with duplicated nervous and organ systems. This effect of praziquantel was selectively ablated by in vivo RNAi of VOCC beta-subunits, but not by knock-down of alpha-subunits. At higher doses of praziquantel, knock-down of VOCC beta-subunit also conferred resistance to praziquantel, confirming the critical involvement of this beta subunit in the action of the drug.

A combined treatment regimen with albendazole and praziquantel given during the month prior to surgery of E. granulosus-infected patients increased the number of human patients with non-viable protoscoleces as compared to therapy with albendazole alone (Cobo et al. 1998). Thus, praziquantel is regarded as useful in cases where cyst content is spilled during surgery.

For the treatment of AE, surgery and chemotherapy are the two only treatment options (Ammann and Eckert, 1995). Spontaneous cure of AE, leading to calcified lesions, is possible, but it is not known how commonly this occurs (Gottstein and Hemphill, 1997; Vuitton, 2009). Radical surgery of viable lesions is carried out if possible, but can be difficult to achieve, and only about one third of all cases are actually operated on. In contrast to E. granulosus metacestodes, E. multilocularis metacestodes are almost exclusively located in the liver. However, metastases can occur, also involving distant sites including lungs, spleen and brain. Chemotherapy should last for at least 2 years post-surgery, and monitoring of patients should be continued for 10 years. Inoperable cases must undergo long-term chemotherapy, often life-long (Reuter et al. 2000; 2004; Vuitton, 2009). The experiences with longterm use of benzimidazoles has had an enormous 
impact on the use of surgery. Generally, palliative surgery should be avoided and replaced by benzimidazole treatment alone or combined with percutaneous or perendoscopic interventions to treat biliary or vascular complications (Bresson-Hadni et al. 2000, 2006; Vuitton, 2009). Extensive animal experimentation and clinical experience in human patients have both demonstrated that albendazole and mebendazole exhibit a parasitostatic rather than parasiticidal effect against E. multilocularis metacestodes (Reuter et al. 2004; Vuitton, 2009). Thus benzimidazoles only prevent parasite growth, and the recurrence rates after interruption of therapy are high. Nevertheless, clinical studies have shown that chemotherapy has significantly increased the 10 -year survival rate of inoperable or non-radically operated AE patients from $6-25 \%$ to $80-83 \%$ (Hemphill et al. 2007).

Benzimidazoles are generally well tolerated, but problems can occur. Adverse reactions include hepatotoxicity, alopoecia, gastrointestinal disturbances and leukopaenia, which is sometimes severe and irreversible (Horton, 1997). Risks also include embryotoxicity and teratogenicity. In order to improve bioavailability, liposome-entrapped formulations and emulsions of albendazole have been tested (Wen et al. 1996; Chai et al. 2004). The use of cimetidine is discouraged, since it increases intestinal absorption (Wen et al. 1996; Schipper et al. 2000), which in turn could result in toxic effects.

Major problems associated with benzimdazoles are the intra- and inter-individual variations of the pharmacokinetics, which make it necessary to measure albendazole sulphoxide and mebendazole plasma levels on a regular basis in order to adjust drug dosage and to avoid toxicity (Vuitton, 2009). This is only possible in specialized facilities, and thus precludes the use of benzimidazoles in those endemic areas where efficient drugs would be mostly needed. In addition, it is unknown whether there is a stagespecific response to exposure to benzimidazoles, and the actual concentration at the site where the drug exerts its action is not known. These pharmacological uncertainties, together with the difficulties in assessing metacestode viability in humans, show that novel and improved chemotherapeutical tools are needed in order to optimize the treatment of $\mathrm{CE}$ and $\mathrm{AE}$.

THE ROLE OF IN VITRO CULTURE IN DRUG DISCOVER Y

In order to identify novel potential alternatives for chemotherapy against echinococcosis, the strategy used most commonly has been whole organism screening of E. multilocularis and E. granulosus metacestodes and/or protoscoleces. In most cases, researchers have focused on broad-spectrum antiinfective agents and anti-cancer compounds, many of which also exhibited reasonable efficacy against Echinococcus (Hemphill and Müller, 2009).

In vitro chemotherapy studies on $\mathrm{CE}$ have mostly, but not exclusively, been carried out on protoscoleces, since these are easily obtained from cysts of an infected animal. The metabolism, and thus drug-susceptibility, of E. granulosus protoscoleces might however be different from the metacestode stage tissue. As an example, praziquantel is highly active against adult tapeworms and against protoscoleces, but only of limited efficacy against metacestodes. Conversely, albendazole is less active against protoscoleces, but of significantly higher efficacy against metacestodes (Taylor et al. 1989).

Infection of laboratory animals with E. granulosus protoscoleces results in the development of metacestodes, which mimics the process of secondary hydatid disease in humans, and this differentiation process can also be achieved in vitro (Walker et al. 2004). E. granulosus metacestodes do not proliferate in vitro but, as in vivo, show a marked increase in size. Thus, extensive animal experimentation is necessary for constant supply of metacestode material. In contrast, E. multilocularis metacestodes, besides increasing in size, also proliferate asexually and, provided with the corresponding nutrients and growth factors, will form new vesicles either endogenously (from within the germinal layer) or exogenously (by budding of daughter metacestodes from older vesicles; Fig. 3). Thus, the fact that E. multilocularis metacestodes proliferate in vitro has rendered this model suitable for the experimental assessment of the effects of chemotherapeutically interesting compounds.

Historically, the in vitro culture of E. multilocularis metacestodes was achieved by dissection of infected rodents and placing small pieces of infected tissue or vesicle suspension into a suitable culture medium at $37^{\circ} \mathrm{C}$. After a few weeks, newly formed metacestodes emerged, which were infective when re-introduced back into rodents (Hemphill and Gottstein, 1995). These were co-culture systems, as parasites could be maintained for several months in the presence of feeder cells, and in the absence of feeder cells, metacestodes degenerated within a few weeks. Jura et al. (1996) introduced a second in vitro co-culture system, which was based on co-incubation of homogenized parasite tissue obtained from infected rats with primary rat hepatocytes embedded in a collagen layer. Although useful in many instances (reviewed in Hemphill et al. 2002, 2007; Brehm and Spilitois, 2008a), these co-culture systems provided only moderate yields and only a very limited number of drugs could be studied. Thus, the amount of metacestodes that could be generated was not sufficient for larger scale investigations.

Recently, Spiliotis and Brehm (2008) have overcome this problem and established a large-scale cultivation system which utilizes homogenized 


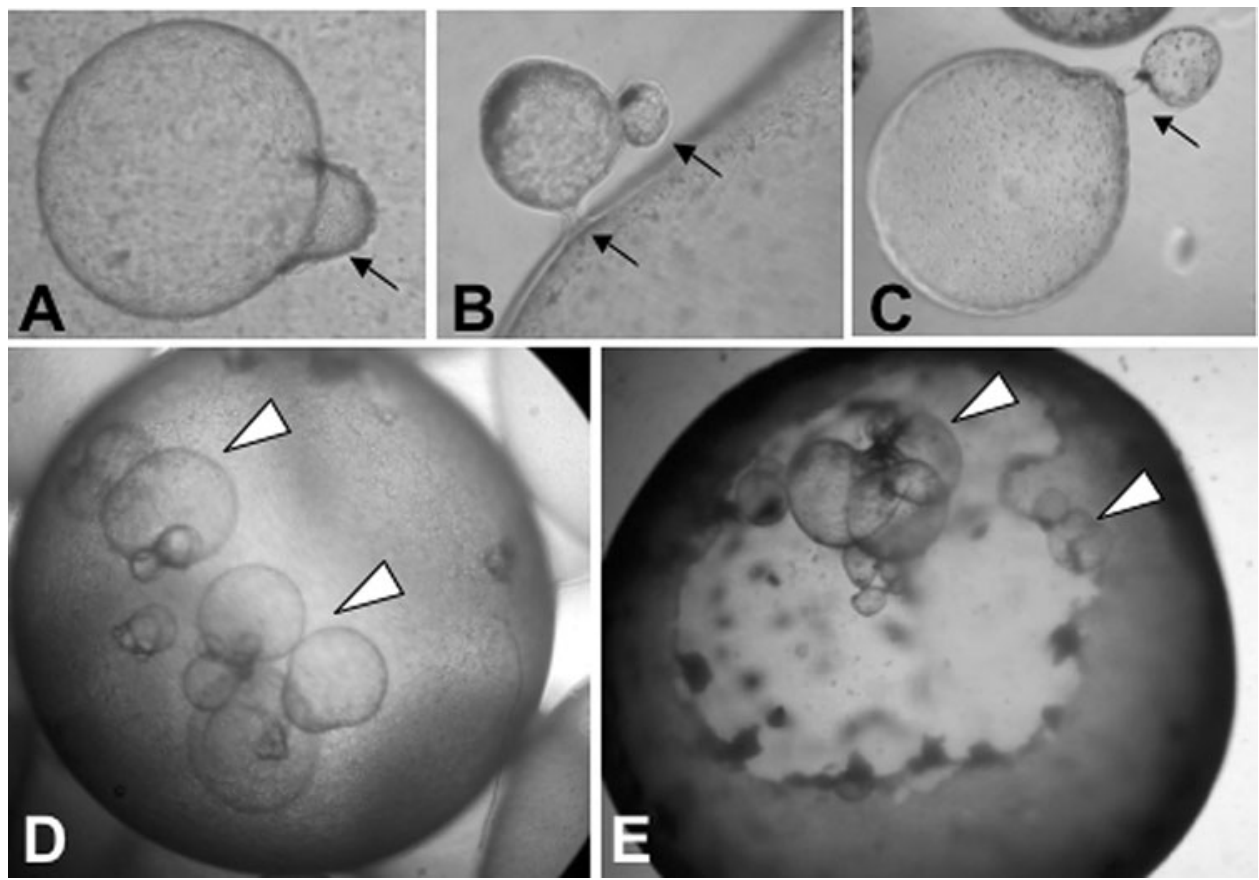

Fig. 3. Exogenous and endogenous proliferation of E. multilocularis metacestodes in vitro. Exogenous outgrowth of a newly formed vesicle (arrows in A-B) from a pre-exisiting parent vesicle appears to be followed by budding off of the daughter vesicle (C). Vesicles are also formed within older metacestodes, most likely by emerging out of the germinal layer, and these smaller metacestodes are released upon desintegration of the older metacestode $(D, E)$.

metacestode tissue that is incubated in liquid culture together with rat hepatoma feeder cells. Using this system, high numbers of metacestodes with comparable sizes can be generated within a few weeks of incubation. Thus, a major task of feeder cells appears to be the provision and secretion of growth factors that are needed by the parasites to undergo proliferation, growth and differentiation. E. multilocularis metacestodes possess several receptors that interact with human epidermal growth factor (EGF), insulin, transforming growth factor-beta and steroid hormones (Brehm et al. 2006; Brehm and Spiliotis, $2008 b$ ), and these most likely allow the parasite to communicate with its host and adapt to alterations in living conditions, regulating gene expression to its favour. Of course, these receptors, and associated signalling pathways within the parasite, represent interesting targets for potential chemotherapeutical intervention (Brehm et al. 2006; Gelmedin et al. 2008). In addition, Spiliotis et al. (2004) developed the methodology to culture $E$. multilocularis metacestodes axenically, in the absence of feeder cells, under reducing and anaerobic conditions. In the presence of oxygen, these metacestodes degenerate within few weeks (Spilitois et al. 2004), illustrating the high sensitivity of $E$. multilocularis metacestodes to oxygen intermediates. The specific adaptation of the mitochondrial respiratory system to anaerobic environments has been shown also for E. multilocularis protoscoleces (Matsumoto et al. 2008). Thus, another important task of feeder cells is to remove toxic oxygen intermediates (Brehm and Spiliotis, 2008a).

METHODS FOR THE ASSESSMENT OF ANTI-ECHINOCOCCAL DRUG CANDIDATES

By using animal experimentation, the primary assessment of anti-echinococcal drug candidates has often been performed in mice or gerbils, through evaluation of parasite mass and/or health parameters of the host. This has led to the extensive use of animal experimentation, but has often yielded inconclusive results (reviewed in Siles-Lucas and Hemphill, 2002). More recently, in vitro cultured Echinococcus metacestodes have been increasingly used for the primary assessment of drug susceptibilities (Hemphill et al. 2002, 2007).

A major problem associated with drug-efficacy assessment has always been the monitoring of the actual metacestode viability following in vitro drug treatment. In a primary evaluation, the effects of in vitro drug treatment can be assessed mainly by visual inspection of morphological alterations and light-microscopy. SEM and TEM have also been used extensively to investigate tissue damage in more detail (Ingold et al. 1999; Stettler et al. 2003; Naguleswaran et al. 2006; Spicher et al. 2008 a ; see also Fig. 2E, F), and nuclear magnetic resonance spectroscopy (NMR) has been applied to investigate metabolic changes imposed upon the parasites by drug treatments (Ingold et al. 1999). Others have 
attempted to assess parasite viability and growth by the quantification of the expression of molecular marker genes such as 14-3-3 and II/3-10 (Matsumoto et al. 2006). Visual inspection relies on subjective observations and thus requires experienced personnel, while other techniques such as SEM, TEM, NMR and RT-real time PCR are intrinsically time-consuming and expensive. Although these approaches have lead to the identification of several compounds with reasonable activities in the micromolar range in vitro (see below), it has not been possible to implement these techniques in a costeffective manner at a larger scale, and they have not always produced conclusive results. For instance, in vitro culture of E. multilocularis metacestodes in the presence of albendazole sulphoxide for 14 days resulted in altered composition of vesicle fluid metabolites as assessed by NMR, and complete destruction of the metacestode structural integrity as visualized by SEM and TEM (Ingold et al. 1999). However, bioassay (re-inoculation of treated parasite material into mice) subsequently showed that the parasite had not been killed completely (Stettler et al. 2003). This was confirmed by Reuter et al. (2006), and illustrates the difficulties in viability assessment following drug treatment.

Although several potentially interesting compounds were identified, and combinations of some of these drugs with albendazole led to slightly improved treatment efficacy in experimentally infected mice or gerbils, none of these compounds exhibited improved activities compared to albendazole (reviewed in Hemphill et al. 2007). Thus, many more drugs and/or compound classes should be investigated, and there is an urgent need for a reliable, but also easyto-handle and rapid in vitro drug screening assay for the identification of chemotherapeutically interesting compounds in vitro.

Attempts to develop screening assays based on the use of vital dyes employed for the assessment of cell viability, such as Alamar blue and Trypan blue, were undertaken. They worked well for protoscolex viability asessment (Walker et al. 2004), but they were not practical when used with metacestodes, as these dyes tend to bind to components of the laminated layer (M. Spicher et al. unpublished observations). The MTT viability assay, which is based on the activity of mitochondrial reductase that reduces yellow 3-(4,5-dimethylthiazol-2-yl)2,5-diphenyltetrazoliumbromide to purple formazan in living cells, worked well for E. multilocularis metacestodes in an experimental setting (Emery et al. 1995), but was not found to be useful for the assessment of larger numbers of compounds (A. Hemphill, unpublished observations).

Another biomarker-based approach to develop such a screening assay could be to identify specific enzyme activities in culture supernatant obtained from drug-treated parasites, which release vesicle fluid components once they are damaged or structurally impaired upon exposure to an active compound. Such biomarkers indicating damage are not present in culture supernatants of untreated metacestodes. E. multilocularis metacestodes are basically fluid-filled vesicles that are surrounded by an outer, acellular laminated layer, and the inner surface of this laminated layer is delineated by the actual parasite tissue, the germinal layer. The germinal layer secretes the components of the laminated layer towards the metacestode periphery into the laminated layer, and also secretes and/or releases metabolites into the vesicle fluid. One enzyme that represents an intrinsic component of the vesicle fluid, and which is also found on the laminated layer, is alkaline phosphatase (AP; Sarciron et al. 1991; Lawton et al. 1997). The detection of AP activity in medium supernatants of drug-treated metacestode cultures has been proposed as a method to screen for active drugs (Stettler et al. 2001). AP-activity was indeed increased in culture supernatants of metacestodes treated with nitazoxanide (Stettler et al. 2003), 2-methoxyestradiol and artemisininderivatives (Spicher et al. 2008a,b), but the sensitivity of this assay was not always satisfactory (Gelmedin et al. 2008; A. Hemphill, unpublished observations). Thus, detection of AP activity does not represent a reliable measure for drug screening in vitro. Another enzyme, phosphoglucose isomerase, released by dying $E$. multilocularis metacestodes, was found to be a promising marker that allows assessment of parasite viability of drug-treated E. multilocularis metacestodes. The potential of this screen for high-throughput assays will be published soon (B. Stadelmann et al. unpublished observations).

Parasite-derived biomarkers could also play a major role for monitoring drug efficacy in patients suffering from echinococcosis during drug trials. For instance, it was previously shown that the serological response of patients against $E$. multilocularis alkaline phosphatase could reflect viability following surgery and/or chemotherapy (Sarciron et al. 1997). Such immunological tests are dependent on the availability and specificity of antigens and do not always provide clear-cut results; the same applies to molecular tests, such as PCR, which require specific primers. Thus, more recently, disease-specific biomarkers have been identified by metabolic profiling emplyoing ${ }^{1} \mathrm{H}$ nuclear magnetic resonance spectroscopy (NMR). This technology delivers an overview of the metabolic composition of biofluids and tissues in diseased versus non-diseased individuals, and such studies have provided the means for detection and differentiation of e.g. coronary heart disease and schizophrenia (Ordovas and Moser, 2006; Holmes et al. 2006). Metabolic profiling has been carried out in rodents infected with $S$. mansoni (Wang et al. 2004), S. japonicum (Wang et al. 2006), T. spiralis (Martin et al. 2006), Trypanosoma brucei brucei (Wang et al. 


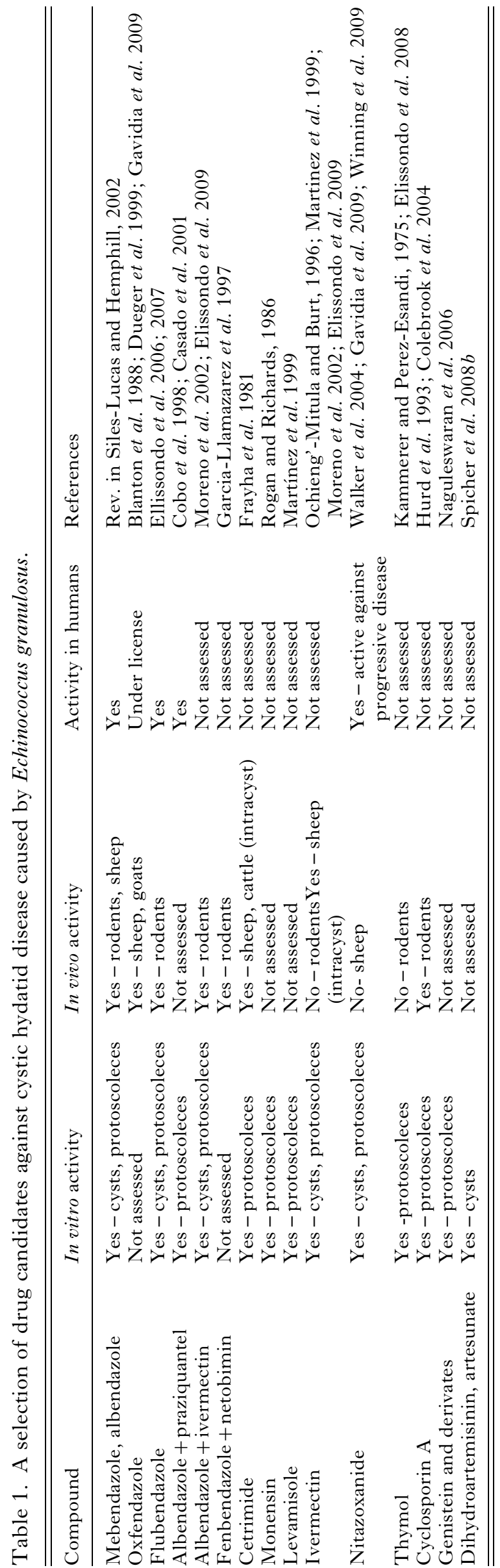

2008), Plasmodium berghei (Li et al. 2008), and Echinostoma caproni (Saric et al. 2008), and could be of high interest for other infections where good markers for disease progression and/or regression are still missing. For instance, a recent study (Hosch et al. 2008) has shown that there is a good correlation between metabolic viability assessment achieved through ${ }^{1} \mathrm{H}$ NMR of E. granulosus cyst fluid measured ex vivo from 50 patients with different degrees of disease classification and the classical ultrasound/light microscopy disease assessment, demonstrating the potential benefit of the use of metabolic biomarkers in disease and parasite viability assessments, e.g. during chemotherapy.

\section{DRUG CANDIDATES FOR THE TREATMENT OF ECHINOCOCCOSIS}

\section{Cystic echinococcosis (CE)}

A selection of drugs and potential drug candidates against $\mathrm{CE}$ is provided in Table 1 . In many instances, in vitro studies on compounds active against E. granulosus have employed protoscoleces. Experimental prophylactic therapy of $E$. granulosus protoscoleces was carried out as a model that would mimic spillage during surgery, by treating protoscoleces with praziquantel (Urrea-Paris et al. 2001) or a combination of praziquantel and albendazole (Casado et al. 2001) prior to injection into mice. The combination of albendazole and praziquantel has been used successfully in the treatment of human CE (Cobo et al. 1998). Other promising compounds with in vitro protoscolicidal actions against $E$. granulosus were cetrimide (Frayha et al. 1981) and the ionophore monensin (Rogan and Richards, 1986), but these drugs were rather ineffective against metacestodes. Levamisole and ivermectin, which are classically used against nematode infections, exhibited in vitro activities similar to benzimidazoles (Martinez et al. 1999; Elissondo et al. 2009). The direct injection of ivermectin into E. granulosus cysts in laparotomised patients has also shown parasiticidal effects (Ochieng'-Mitula and Burt, 1996). The combination of ivermectin plus albendazole has shown synergistic effects in infected mice (Moreno et al. 2002). Benzimidazoles vary considerably with regard to their protoscolicidal action. Albendazole and albendazole sulphoxide have been shown to be active against E. granulosus protoscoleces in vitro (Chinnery and Morris, 1986; Morris et al. 1987; Perez-Serrano et al. 1994), but the in vitro protoscolicidal action of these drugs is rather slow and requires a longer incubation period compared to mebendazole (Morris et al. 1987; Rodriguez-Caabeiro et al. 1989) or oxfendazole, the major fenbendazole sulphoxide metabolite. Against E. granulosus infection in rodents, a combination of fenbendazole and netobimin (Garcia-Llamazarez et al. 1997) showed synergistic effects, allowing the 
administration of lower drug dosages. Oxfendazole, like albendazole, is a benzimidazole, used in veterinary medicine for the treatment of nematode infections, and has a similar antimicrobial spectrum but a longer half-life. Experimental treatments of naturally $E$. granulosus-infected sheep and goats suggested that oxfendazole may be as efficacious as albendazole, but does not require daily uptake of the drug because of its prolonged bioavailability (Blanton et al. 1988; Dueger et al. 1999). Nitazoxanide, a nitro-thiazole-analogue (Hemphill et al. 2006) induced severe damage to E. granulosus protoscoleces and the germinal layer of E. granulosus metacestodes within few days of in vitro culture (Walker et al. 2004). Nitazoxanide treatment was not effective against experimental E. granulosus infection in sheep, but oxfendazole treatment, and a combination of oxfendazole and nitazoxanide, significantly decreased the number of fertile cysts and increased the number of degenerated cysts (Gavidia et al. 2009). On the other hand, a recent case report has suggested beneficial effects of nitazoxanide in the treatment of refractory bony hydatid disease in a human patient (Winning et al. 2009). This patient had been suffering from progressive disease despite treatment with albendazole and praziquantel, and the clinical response on nitazoxanide treatment showed marked improvement in the soft tissue cysts, with stable disease in the bony pelvis. Although further studies are required, this report suggests that nitazoxanide may be an effective treatment option in CE, particularly in patients with progressive disease who are receiving conventional treatment (Winning et al. 2009).

Profound protoscolicidal activity was also reported for another benzimidazole-derivative, flubendazole (Ellissondo et al. 2006, 2009). Further studies subsequently showed that flubendazole also exhibited anti-E. granulosus metacestocidal activities in vitro and in vivo in experimentally infected mice (Elissondo et al. 2007). The same authors, together with Kammerer and Perez-Esandi (1975), showed that thymol, one of the major components of the essential oils of Thymus, was found to exhibit substantial protoscolicidal activity (Elissondo et al. 2008).

Cyclosporin A, employed mainly as an immunosuppressant during the management of organ transplants, also exhibits anti-echinococcal activity. The administration of cyclosporin $\mathrm{A}$ in five consecutive daily doses, beginning 2 days prior to the infection of mice with E. granulosus protoscoleces, resulted in a significant reduction in cyst numbers and cyst masses measured at 20 weeks after infection. However, no changes in cyst mass and numbers were recorded when the drug was administered 18 weeks after infection, but the wet weight was decreased by $42 \%$ compared with untreated controls. Ultrastructural examination of the germinal membrane and laminated layer of late-treated E. granulosus revealed abnormalities in all cysts studied whereas control and early-treated hydatids were normal (Hurd et al. 1993). Cyclosporin A has also been shown to affect E. granulosus protoscoleces in vitro (Colebrook et al. 2004).

\section{Alveolar echinococcosis $(A E)$}

A selection of drugs and potential drug candidates for the treatment of $\mathrm{AE}$ is provided in Table 2 . Cyclosporin A, contrary to what was found in CE, lacked anti-parasitic activity against $E$. multilocularis infection in experimentally infected mice (Liance et al. 1992). Doxorubicin, or hydroxyldaunorubicin, a DNA-interacting drug used widely in the treatment of a wide range of cancers (Launchbury and Habboubi, 1993), was bound to polyisohexylcyanoacrylate nanoparticles (a colloidal biodegradable drug carrier) and applied in E. mutlilocularis-infected mice, resulting in the reduction of the development of the parasite in the liver and a reduced viability of the metacestode. Free doxorubicin or unbound nanoparticles had no antiparasitic activity (Liance et al. 1993). Animal experimentation in rodents demonstrated parasitostatic effects of mytomicin $\mathrm{C}$, piperazine and quinolone derivates, alkylaminoethers and propargylic alcohols, either at a lower level or comparable to benzimidazoles (reviewed in Siles-Lucas and Hemphill, 2002). The efficacy of praziquantel was inadequate (Marchiondo et al. 1994), although showing some effects on protoscoleces in vitro (Taylor and Morris, 1988). Also, the treatment of $E$. multilocularis-infected mice with alpha-difluoromethylornithine was not successful (Miyaji et al. 1993).

More recently, studies on chemotherapeutically interesting compounds have employed in vitro cultured parasites. Nitazoxanide, a broad-spectrum anthelminthic also used for treatment against enteric bacteria, Giardia and Cryptosporidium (Hemphill et al. 2006), was identified as a compound inducing significant distortion of the germinal layer in vitro, and nitazoxanide-treated E. multilocularis metacestodes were non-viable when introduced into susceptible mice (Stettler et al. 2003). Reuter et al. (2006) investigated the in vitro efficacy of a series of compounds against E. multilocularis metacestodes, including albendazole, artemether, caspofungin, itraconazole, ivermectin, methiazole, miltefosine, nitazoxanide, rifampicin and trimethoprim/sulfamethoxazole. They found that albendazole, itraconazole, methiazole and nitazoxanide effectively destroyed parasite vesicles in vitro. However, after drug discontinuation, re-growth of vesicles occurred, indicating a parasitostatic effect only. Combination treatment with albendazole/nitazoxanide at concentrations between 1 and $10 \mu \mathrm{g} / \mathrm{ml}$ for 3 weeks yielded no re-growth of parasites during 8 months of 
Table 2. A selection of drug candidates against alveolar echinococcosis caused by Echinococcus multilocularis

\begin{tabular}{|c|c|c|c|c|}
\hline Compound & In vitro activity & In vivo activity & Activity in humans & References \\
\hline Cyclosporin A & Not assessed & No - rodents & Not assessed & Liance et al. 1992 \\
\hline Doxorubicin and colloidal carrier & Not assessed & Yes - rodents & Not assessed & Liance et al. 1993 \\
\hline $\begin{array}{l}\text { Mitomycin C, piperazine and derivates, } \\
\text { alkylaminoethers, propargylic alcohols }\end{array}$ & Not assessed & Yes - rodents & Not assessed & Rev. in Siles-Lucas and Hemphill, 2002 \\
\hline Praziquantel & Yes - protoscoleces & No - rodents & Not assessed & Taylor and Morris, 1988; Marchiondo et al. 1994 \\
\hline Mebendazole, albendazole* & $\begin{array}{l}\text { Yes - metacestodes, } \\
\text { protoscoleces }\end{array}$ & Yes - rodents & Yes & Rev. in Siles-Lucas and Hemphill, 2002 \\
\hline Flubendazole & Not assessed & Yes - rodents & No & Rev. in Siles-Lucas and Hemphill, 2002 \\
\hline Itraconazole*, methiazole* & Yes - cysts & Not assessed & Not assessed & Reuter et al. 2006 \\
\hline$\alpha$-difluoromethyl-ornithine & Not assessed & No - rodents & Not assessed & Miyaji et al. 1993 \\
\hline $\begin{array}{l}\text { Nitazoxanide* or } \\
\text { nitazoxanide + albendazole }\end{array}$ & Yes - metacestodes & Yes - rodents & $\begin{array}{l}\text { Only case reports. } \\
\text { Nitazoxanide alone not effective. } \\
\text { Some limited activity in } \\
\text { combination with albendazole. } \\
\text { Needs more studies }\end{array}$ & $\begin{array}{l}\text { Stettler et al. 2003, 2004; Reuter et al. 2006; } \\
\text { Kern } \text { et al. } 2008\end{array}$ \\
\hline $\begin{array}{l}\text { Artemether, caspofungin, } \\
\text { ivermectin, miltefosine, } \\
\text { rifampicin, trimethoprim } \\
\text { /sulfamethoxazole }\end{array}$ & No- metacestodes & Not assessed & Not assessed & Reuter et al. 2006 \\
\hline Amphotericin B desoxycholate* & Yes - metacestodes & Not assessed & Yes (intravenous) & Reuter et al. $2003 a, b$ \\
\hline Genistein and derivates & Yes - metacestodes & Not assessed & Not assessed & Naguleswaran et al. 2006 \\
\hline Pyridinyl imidazoles & Yes - metacestodes & Not assessed & Not assessed & Gelmedin et al. 2008 \\
\hline 2-Methoxyestradiol & Yes - metacestodes & No - rodents & Not assessed & Spicher et al. $2008 a$ \\
\hline Dihydroartemisinin, artesunate & Yes - metacestodes & No- rodents & Not assessed & Spicher et al. $2008 b$ \\
\hline Isoprinosine and derivates & Yes - protoscoleces & Yes - rodents & Not assessed & Lawton et al. 2001 \\
\hline
\end{tabular}

* Parasitostatic 
drug discontinuation, and the subsequent evaluation in a bioassay in gerbils did also not result in viable parasite infections. In this respect, Stettler et al. (2004) showed that nitazoxanide, applied orally to E. multilocularis infected mice, either alone or in combination with ABZ, exhibited a profound antiparasitic efficacy, with the albendazole/nitazoxanide combination yielding the most promising outcome in terms of reducing parasite weight. The pharmacokinetic analysis of corresponding serum levels in mice showed that the application of albendazole in combination with nitazoxanide increased considerably the levels and the half-life of albendazole sulfoxide (Stettler et al. 2004). Therefore, the increased efficacy observed in mice could be the result of an increased availability of albendazole sulfoxide in mice receiving the combination treatment. Despite these promising results, neither nitazoxanide monotherapy nor nitazoxanide-albendazole combination therapies were highly effective in human patients sufffering from AE (Kern et al. 2008).

Amphotericin B desoxycholate (cAMB), an antifungal compound, effectively inhibited the growth of E. multilocularis metacestodes, first in vitro, and subsequently in human patients in vivo (Reuter et al. 2003a,b). A major limitation of cAMB is its mode of administration (intra-venous), which makes it unsuitable for prolonged use, except for salvage treatment (Reuter et al. $2003 \mathrm{~b}$ ). Also, the action of cAMB is only parasitostatic and, since the drug is nephrotoxic, its widespread use is limited. Nevertheless, prolonged application of cAMB for months to years may be feasible in some cases, as side effects are mild and serious organ damage does not appear to occur (Reuter et al. 2003 b).

In vitro studies on $E$. multilocularis metacestodes and E. granulosus protoscoleces have shown that genistein, representing a major component of soya and the most prominent isoflavonoid, as well as a number of genistein derivatives, are also highly effective against these parasites. The molecular basis of the efficacy of genistein and its derivative Rm6423 have not yet been elucidated, but these compounds could interfere in signalling, for instance, through an inhibition of the tyrosine kinase activity associated with the epidermal growth factor receptor identified in E. multilocularis (see Brehm et al. 2006). Recently, Gelmedin et al. (2008) identified pyridinyl imidazoles as ATP-competitive inhibitors of a p38-like mitogen-activated protein kinase (MAPK) of $E$. multilocularis by adding them to in vitro cultures, demonstrating death of parasite vesicles at concentrations that did not affect cultured mammalian cells.

An endogenous metabolite of oestrogen with both anti-angiogenic and anti-tumour effects, 2methoxyestradiol (2-ME) (reviewed by Schumacher and Neuhaus, 2001) was shown to induce severe damage to $E$. multilocularis metacestodes in vitro in a dose-dependent manner (Spicher et al. 2008a). However, 2-ME-treatment of experimentally infected mice did not result in a reduction in parasite weight compared to the control, demonstrating that in vitro and in vivo situations are not always comparable. Best results were achieved with a treatment using a combination of 2-ME and albendazole, which lead to a reduction in parasite weight compared to albendazole treatment alone, but results did not show statistical significance (Spicher et al. 2008a). In vitro treatment of E. multilocularis and E. granulosus larval stages with the antimalarials dihydroartemisinin and artesunate exhibited promising results, while 6 weeks of in vivo treatment of mice with infected E. multilocularis metacestodes had no effect. Again, combination treatments of both drugs with albendazole led to a substantial but statistically not significant reduction in parasite weight compared to results with albendazole alone (Spicher et al. 2008b).

The in vitro effect of isoprinosine and its derivates has also been demonstrated against protoscoleces of E. multilocularis (Lawton et al. 2001).

RELEVANCE OF ECHINOCOCCUS METACESTODE SCREENING MODELS FOR OTHER CESTODES AND TREMATODES

Numerous studies have demonstrated that many of those drugs that were active in E. granulosus drug screening models were also of significant relevance for $E$. multilocularis and vice versa (see above). In addition, there is ample evidence that most compounds with good in vitro and in vivo efficacy against Echinococcus metacestodes are also of relevance for combatting infections by other cestode larval stages. For instance, cysticerci of T. taeniaeformis were highly sensitive to praziquantel (Becker et al. 1981), and the same applied to $T$. solium and T. pisiformis (Garcia-Dominguez et al. 1991; Martinez Zedillo et al. 1992). Albendazole and mebendazole (or modified derivatives) were also active against $T$. taeniaeformis cysticerci in experimentally infected mice (Verheyen et al. 1978; Jain et al. 1989). To date, albendazole and praziquantel, taken as short-term treatments (8-15 days) are the main drugs of choice for chemotherapeutic treatment of neurocysticercosis in humans (Garcia et al. 2003; Shandera and Kass, 2006). A recent in vitro study on $T$. crassiceps indicates that a combination of nitazoxanide and albendazole could be used for the treatment of cysticercosis infections (PalomaresAlonso et al. 2007), but in vivo evidence is still lacking. The effects of other benzimidazoles, such as flubendazole, were evaluated in T. solium-infected swine, with promising results (Tellez-Giron et al. 1981) that were subsequently confirmed in human patients (Tellez-Giron, 1984).

The activity of benzimidazole derivatives against Hymenolepis larvae was evaluated in the intermediate 
host Tribolium confusum, demonstrating clear effects with regard to larval development (Novak and Blackburn, 1985). However, in the rodent model it was shown that benzimidazole drugs were only effective against $H$. nana oncosphere infection, but already developed cysticercoids were difficult to cure (Gupta et al. 1981; Maki and Yanagisawa, 1985), and neither flubendazole nor thiabendazole could clear $H$. nana cysticercoid infections in mice. Mebendazole and a series of modified benzimidazole derivatives were effective against $H$. nana and H. diminuta cysticercoids (Dubey et al. 1985).

In vitro studies on the effects of exposure of Mesocestoides corti tetrathyridia to anti-parasitic drugs revealed that liposomized praziquantel and albendazole had a deleterious effect on the parasite morphology and development (Hrckova et al. 1998; Britos et al. 2000; Saldana et al. 2001). The efficacy and mode of action of praziquantel were studied in the mouse model, showing that application of praziquantel had an adverse effect on the tetrathyridia burden in the liver and peritoneum (Hrckova and Velebny, 1995, 1997). Following the oral administration of mebendazole to $M$. corti-infected mice, a parasiticidal effect was observed (Heath et al. 1975; Eckert and Pohlenz, 1976). This is in contrast to other cestode larvae, against which mebendazole exerts a parasitostatic effect only. Deleterious actions of other drugs on Mesocestoides tetrathyridia, including cyclosporin A (Chappell et al. 1989) and albendazole (Terenina et al. 1998), have also been reported.

Potentially, the Echinococcus screening models could also have some, albeit limited, relevance for a number of trematode species, including Schistosoma japonicum, S. manoni, Chlonorchis sinensis, Fasciola hepatica and Opistorchis viverrini. For instance, praziquantel is the drug of choice for the treatment of schistosomiasis (King, 2007). The drug is highly effective against the adult worm (as for cestodes), but has only a minor activity against the larval schistosomula. Another class of drugs that show similarities between Echinococcus and trematodes are the artemisinins and synthetic trioxolanes. These antimalarial drugs possess a broad spectrum of activity against trematodes, causing profound damage in vitro and substantially reducing the worm burden in experimentally infected mice (reviewed by Keiser and Utzinger, $2007 a, b$ ). Echinoccoccus metacestodes were also susceptible to artesunate and dihydroartemisinin in vitro, while the schistosomula were found to be particularly susceptible to artemether and artesunate (Utzinger et al. 2002; Spicher et al. $2008 \mathrm{~b}$ ). The promising activity of mefloquine, another anti-malarial drug, in mice experimentally infected with S. japonicum and S. mansoni, has been reported (Keiser et al. 2009), and recent studies in our laboratory also revealed that mefloquine has a profound impact on in vitro cultured E. multilocularis metacestodes (A. Hemphill et al. unpublished observations).

On the other hand, albendazole and mebendazole, the main anti-echinococcal drugs, have no impact on S. mansoni (Schmidt, 1998). In contrast, flubendazole, a mebendazole-derivative, was active against $S$. mansoni in experimentally infected mice (Nessim et al. 2000; Williams et al. 2003), and another benzimdazole, triclabendazole, was active against Fasciola hepatica (Robinson et al. 2001). As for Echinococcus, F. hepatica was susceptible to nitazoxanide treatment in vitro, and clinical studies showed that nitazoxanide could be used for the treatment of fasciolasis in children and adults (reviewed in Hemphill et al. 2006).

\section{WHERE TO GO FROM HERE?}

As outlined in this review, considerable efforts have been undertaken to improve the therapeutic options for the treatment of $\mathrm{CE}$ and $\mathrm{AE}$ (reviewed in Vuitton, 2009). These efforts have largely concentrated on the establishment of procedures on how to manage the diseases and by setting up guidelines for treatment and classifications of disease status. Although most successful to a large extent, the current benzimidazole-based chemotherapy is far from optimal and, owing to the limited efficacy of this class of compounds, their side-effects and their costs, alternative drugs or drugs that could be integrated into a combination treatment are clearly needed. Thus, considerably more input and support is needed from academic institutions as well as pharmaceutical and biotechnological industries and governmental agencies to provide solutions for these neglected diseases. A recent survey on the financial resources going into research and development funding in 2007 has shown, that HIV/AIDS received $1 \cdot 1$ billion US dollars, malaria and tuberculosis obtained over 400 million US dollars each, and kinetoplastid diseases and diarrhoeal diseases were granted over 125 and 114 million dollars each. On the other hand, helminth infections as a whole, encompassing nematodes, cestodes and trematodes, received only 51.6 million dollars (Voelker, 2009).

But finances alone will not provide novel possibilities. Until recently, Echinococcus drug discovery has been based on rather anecdotal reports, where a limited number of drugs belonging to a certain compound class have been investigated. However, the Echinococcus drug discovery process has been lacking several important aspects that are compulsary for successfully identifying the best and most interesting compounds. First, we need to gain access to comprehensive compound libraries, and we need to be able to screen these libraries. This can only be done through the implementation of easy-tohandle and reliable medium-to-high-throughput in vitro assays that allow screening of larger numbers of 
anti-parasitic drugs in an efficient manner. Preferentially, these assays do not rely on subjective microscopic evaluation, but on objective criteria, such as specific markers (e.g. enzyme activities) that indicate parasite viability/intactness or non-viability/ damage, and which could be detected preferentially in an (at least) semi-automated system. The development of such assays is ongoing, but should be intensified.

Secondly, large-scale drug screening activities are only possible if sufficient numbers of parasite organisms can be generated in vitro. This prerequisite has been fullfilled due to the pioneering work of Brehm and co-workers (see Spiliotis and Brehm, 2008), who developed an E. multilocularis metacestode in vitro culture system that allows the generation of massive numbers of metacestodes out of a relatively small quantity of parasite tissue. This does not only enable researchers to carry out numerous drugscreening assays, but also provides the basis for biochemical studies, including the identification of drug targets for specific compounds by affinity chromatography and mass spectrometry-based sequencing.

Thirdly, it is important to have access to genomic and EST databases. In 2008, shotgun sequencing of the E. multilocularis genome was completed (http://www.sanger.ac.uk/Projects/Echinococcus/). This opens the door for increased use of in silico approaches for drug target identification, similar to the discovery of the anti-metacestodicidal activity of clarithromycin reported by Mathis et al. already in 2005. In addition, the availiability of a genome database permits drug target identification by affinity chromatography of parasite extracts on drugcoupled matrices and subsequent protein identification by mass spectroscopy (Müller et al. $2008 a, b$ ).

Furthermore, a system is required to verify putative drug targets and investigate their functional role, preferentially by genetic means, such as overexpression or silencing of genes of interest. The basis for this was set in 2008, when a method for the long-term in vitro cultivation and proliferation of primary cells isolated from axenically grown E. multilocularis metacestodes was established by Spiliotis et al. (2008). Isolated E. multilocularis cells were transiently transfected with a plasmid carrying the gene coding for the cyano-fluorescent-protein (CFP), and the corresponding gene product was expressed and detected by Western blot analysis. When co-cultured with hepatocytes, cultured $E$. multilocularis cells form aggegates, and eventually undergo complete in vitro regeneration of metacestode vesicles. Prospectively, this could well lead to the development of transgenic larval stages, and even adult $E$. multilocularis worms, and genetic tools can be exploited to elucidate the exact functional role of putative drug targets in different stages of development (reviewed in Brehm and Spiliotis, $2008 a)$.
Finally, the in vitro activity of a compound that exhibits outstanding performance can be verified in vivo, initially preferentially in a relevant small laboratory animal model. The murine or gerbil models for primary and secondary AE (Stettler et al. 2004; Reuter et al. 2006) represent reliable tools for such in vivo studies.

\section{CONCLUSIONS}

Approximately 2 billion helminth infections occur in humans worldwide, and these involving the larval stages of the three cestodes E. multilocularis, E. granulosus and T. solium are among the most serious and life-threatening ones (Brehm et al. 2006). From a practical point of view, the E. multilocularis model, in contrast to other cestodes, clearly fulfills the criteria that would allow for intensified drugscreening processes. It displays advantages such as rapid growth and proliferation in vitro, access to comprehensive genomic information and ESTdatabases, the possibility to maintain parasite isolates routinely in laboratory mice, and to verify in vitro results in a relevant in vivo model. Currently, the monitoring of therapy effectiveness in humans is based methods based on PET scan using ${ }^{18} \mathrm{~F}$-deoxyglucose (Reuter et al. 2004). After optimization, such methods could be used for the follow-up of suitable drug candidates in mice or gerbils thereby further reducing the number of animals per study. Compounds that not only act parasitostatic but also parasitocidal against Echinococcus in vivo have not been discovered to date, but it is conceivable that such compounds exist, and that they would be a very useful addition to the arsenal of anti-parasitic drugs against cestodes and trematodes.

\section{ACKNOWLEDGEMENTS}

We apologize to those authors whose contributions could not be cited in this paper. This work was supported through the National Science Foundation (31-111780), the Novartis Research Foundation, Helvetia Sana Foundation, and the Swiss Life Jubiläumsstiftung. JM is a recipient of a research fellowship provided by Novartis Animal Health, and BS has been supported by the Karl Enigk Stiftung.

\section{REFERENCES}

Ali-Khan, Z., Siboo, R., Gomersall, M. and Faucher, M. (1983). Cystolytic events and the possible role of germinal cells in metastasis in chronic alveolar hydatidosis. Annals of Tropical Medicine and Parasitology 77, 497-512.

Ammann, R. and Eckert, J. (1995). Clinical diagnosis and treatment of echinococcosis in humans. In Echinococcosis and Hydatid Disease (ed. Thompson, R. C. A. and Lymbery, A. J.), pp. 411-430. CAB International, Wallmingford.

Angelucci, F., Basso, A., Bellelli, A., Brunori, M., Pica Maattoccia, L. and Valle, C. (2007). The 
anti-schistosomal drug praziquantel is an adenosine antagonist. Parasitology 134, 215-1221.

Becker, B., Mehlhorn, H., Andrews, P. and Thomas, H. (1981). Ultrastructural investigations on the effect of praziquantel on the tegument of five species of cestodes. Zeitschrift für Parasitenkunde 64, 257-269.

Blanton, R. E., Wachira, T. M., Zeyhle, E., Njoroge, E. M., Magambo, J. K. and Schantz, P. M. (1988). Oxfendazole treatment of cystic hydatid disease in naturally infected animals. Antimicrobial Agents and Chemotherapy 42, 601-605.

Brehm, K. and Spiliotis, M. (2008a). Recent advances in the in vitro cultivation and genetic manipulation of Echinococcus multilocularis metacestodes and germinal cells. Experimental Parasitology 119, 506-515.

Brehm, K. and Spiliotis, M. (2008b). The influence of host hormones and cytokines on Echinococcus multilocularis signalling and development. Parasite 15, 286-289.

Brehm, K., Spiliotis, M., Zavala-Gongora, R., Konrad, C. and Frosch, M. (2006). The molecular mechanisms of larval cestode development: first steps into an unknown world. Parasitology International 55, S15-S21.

Bresson-Hadni, S., Delabrousse, E., Blagosklonov, O., Bartholomot, B., Koch, S., Miguet, J. P., André Mantion, G. and Angèle Vuitton, D. (2006). Imaging aspects and non-surgical interventional treatment in human alveolar echinococcosis. Parasitology International 55 (Suppl.), S267-S272.

Bresson-Hadni, S., Vuitton, D. A., Bartholomot, B., Heyd, B., Godart, D., Meyer, J. P., Hrusovsky, S., Becker, M. C., Mantion, G., Lenys, D. and Miguet, J. P. (2000). A twenty year history of alveolar echinococcosis: analysis of a series of 117 patients from eastern France. European Fournal of Gasteroenterology and Hepatology 12, 327-336.

Britos, L., Dominguez, L., Ehrlich, R. and Marin, M. (2000). Effect of praziquantel on the strobilar development of Mesocestoides corti in vitro. Fournal of Helminthology 74, 295-299.

Brunetti, E., Troia, G., Garlaschelli, A. L., Gulizia, R. and Filice, C. (2004). Twenty years of percutaneous treatments for cystic echinococcosis: a preliminary assessment of their use and safety. Parassitologia 46, $367-370$.

Budke, C. M. (2006). Global socioeconomic impact of cystic echinococcosis. Emerging Infectious Diseases 12, 296-303.

Chappell, L. H., Wastling, J. M. and Hurd, H. (1989). Action of cyclosporin A on the tapeworms Hymenolepis microstoma, $H$. diminuta and Mesocestoides corti in vivo. Parasitology 98, 291-299.

Casado, N., Urrea-Paris, M. A., Moreno, M. J. and Rodriguez-Caabeiro, F. (2001). Combined praziquantel and albendazole chemoprophylaxis in experimental hydatidosis. Parasitology Research 87, 787-789.

Chai, J., Menghebat Wie, J., Deyu, S., Bin, L., Jincao, S., Chen, F., Xiong, L., Yiding, M., Xiuling, W., Dolikun, Guliber, Yanchun, W., Fanghua, G. and Shuhua, X. (2004). Observations on clinical efficacy of albendazole emulsion in 264 cases of hepatic cystic echinococcosis. Parasitology International 53, 3-10.
Chinnery, J. B. and Morris, D. L. (1986). Effects of albendazole sulphoxide on viability of hydatid protoscoleces in vitro. Transactions of the Royal Society of Tropical Medicine and Hygiene 80, 815-817.

Cobo, F., Yarnoz, C., Sesma, B., Fraile, P., Aizcorbe, M., Trujillo, R., Diaz-de-Liano, A. and Ciga, M. A. (1998). Albendazole plus praziquantel versus albendazole alone as preoperative treatment in intra-abdominal hydatidosis caused by Echinococcus granulosus. Tropical Medicine and International Health $\mathbf{3}$, 462-466.

Colebrook, A. L., Jenkins, D. J., Jones, M. K., Tatarczuch, L. and Lightowlers, M. W. (2004). Effect of cyclosporin A on the survival and ultrastructure of Echinococcus granulosus protoscoleces in vitro. Parasitology 129, 497-504.

Craig, P. S., McManus, D. P., Lightowlers, M. W., Chabalgoity, J. A., Garcia, H. H., Gavidia, C. M., Gilman, R. H., Gonzalez, A. E., Lorca, M., Naquira, C., Nieto, A. and Schantz, P. M. (2007). Prevention and control of cystic echinococcosis. Lancet Infectious Diseases 7, 385-394.

Dubey, R., Abuzar, S., Sharma, S., Chatterjee, R. K. and Katiyar, J. C. (1985). Synthesis and anthelmintic activity of 5(6)-(benzimidazol-2-ylcarbamoyl) and (4-substituted piperazin-1-yl)benzimidazoles. Fournal of Medical Chemistry 28, 1748-1750.

Dueger, E. L., Moro, P. L. and Gilman, R. H. (1999). Oxfendazole treatment of sheep with naturally acquired hydatid disease. Antimicrobial Agents and Chemotherapy 43, 2263-2267.

Eckert, J. and Deplazes, P. (2004). Biological, epidemiological, and clinical aspects of echinococcosis, a zoonosis of increasing concern. Clinical Microbiology Reviews 17, 107-135.

Eckert, J. and Pohlenz, J. (1976). On the effect of mebendazole on metacestodes of Mesocestoides corti and Echinococcus multilocularis. Tropenmedizin und Parasitologie 27, 247-262.

Eckert, J., Thompson, R. C. A. and Mehlhorn, H. (1983). Proliferation and metastases formation of larval Echinococcus multilocularis. I. Animal model, macroscopical and histological findings. Zeitschrift für Parasitenkunde 69, 737-748.

Elissondo, M. C., Albani, C. M., Gende, L., Eguaras, M. and Denegri, G. (2008). Efficacy of thymol against Echinococcus granulosus protoscoleces. Parasitology International 57, 185-190.

Elissondo, M. C., Ceballos, L., Alvarez, L., Sánchez Bruni, S., Lanusse, C. and Denegri, G. (2009). Flubendazole and ivermectin in vitro combination therapy produces a marked effect on Echinococcus granulosus protoscoleces and metacestodes. Parasitology Research. doi. 10.1007/s00436-009-1469-y

Elissondo, M., Ceballos, L., Dopchiz, M., Andresiuk, V., Alvarez, L., Sanchez Bruni, S., Lanusse, C. and Denegri, G. (2007). In vitro and in vivo effects of flubendazole on Echinococcus granulosus metacestodes. Parasitology Research 100, 1003-1009.

Elissondo, M. C., Dopchiz, M. C., Ceballos, L., Alvarez, L., Sanchez Bruni, S., Lanusse, C. and Denegri, G. (2006). In vitro effects of flubendazole 
on Echinococcus granulosus protoscoleces. Parasitology Research 98, 317-323.

El-On, J. (2002). Benzimidazole treatment of cystic echinococcosis. Acta Tropica 85, 243-252.

Emery, I., Bories, C., Liance, M., and Houin, R. (1995). In vitro quantitative assessment of Echinococcus multilocularis metacestode viability after in vivo and in vitro maintenance. International Fournal for Parasitology 25, 275-278.

Franchi, C., DiVico, B. and Teggi, A. (1999). Long term evaluation of patients with hydatidosis treated with benzimidazole carbamates. Clinical Infectious Diseases 29, 304-309.

Frayha, G. J., Bikhazi, K. J. and Kachachi, T. A. (1981). Treatment of hydatid cysts (Echinococcus granulosus) by Cetrimide. Transactions of the Royal Society of Tropical Medicine and Hygiene 75, 447-450.

Garcia, H. H., Gonzales, A. E., Evans, C. A. W. and Gilman, R. H. (2003). Taenia solium cysticercosis. The Lancet 361, 547-556.

Garcia-Dominguez, C., Correa, D., Rabiela, M. T. and Flisser, A. (1991). Praziquantel treatment of muscle Taenia solium cysticercosis. 4 . Reversible in vitro effect. Parasitology Research 77, 691-696.

Garcia-Llamazares, J. L., Alvarez-de-Felipe, A. I., Redondo-Cardena, P., Voces-Alonso, J. A. and Prieto-Fernandez, J. G. (1997). In vivo inhibition of the regenerative capacity of hydatid material after treatment with netobimin. Parasitology Research 83, 105-108.

Gavidia, C. M., Gonzalez, A. E., Lopera, L., Jayashi, C., Angelats, R., Barron, E. A., Ninaquispe, B., Villareal, L., Garcia, H. H., Verastegui, M. R. and Gilman, R. (2009). Evaluation of nitazoxanide and oxfendazole efficacy against cystic echinococcosis in naturally infected sheep. American Fournal of Tropical Medicine and Hygiene 80, 367-372.

Gelmedin, V., Caballero-Gamiz, R. and Brehm, K. (2008). Characterization and inhibition of a p38-like mitogen-activated protein kinase (MAPK) from Echinococcus multilocularis: Antiparasitic activities of a p38 MAPK inhibitors. Biochemical Pharmacology 76, 1068-1081.

Gnanasekar, M., Salunkhe, A. M., Mallia, A. K., He, Y. X. and Kalyanasundaram, R. (2009). Prazquantel affects the regulatory myosin light chain of Schistosoma mansoni. Antimicrobial Agents and Chemotherapy 53, 1054-1060.

Gottstein, B. and Hemphill, A. (1997). Immunopathology of echinococcosis. Chemical Immunology 66, 177-208.

Gupta, S., Katiyar, J. C. and Sen, A. B. (1981). Effect of mode of infection on the development and chemotherapeutic response of Hymenolepis nana in rats. Fournal of Helminthology 55, 101-107.

Heath, D. D., Christie, M. J. and Chevis, R. A. (1975). The lethal effect of mebendazole on secondary Echinococcus granulosus, cysticerci of Taenia pisiformis and tetrathyridia of Mesocestoides corti. Parasitology 70, 273-285.

Hemphill, A. and Gottstein, B. (1995). Immunological and morphological studies on the proliferation of in vitro cultivated Echinococcus multilocularis metacestodes. Parasitology Research 81, 605-614.
Hemphill, A. and Kern, P. (2008). Special issue: experimental studies in echinococcosis. Experimental Parasitology 119, 437-438.

Hemphill, A. and Mueller, J. (2009). Alveolar and cystic echinococcosis: towards novel chemotherapeutical treatment options. Fournal of Helminthology 83, 99-111.

Hemphill, A., Mueller, J. and Esposito, M. (2006). Nitazoxanide, a broad-spectrum thiazolide anti-infective agent for the treatment of gastrointestinal infections. Expert Opinion in Pharmacotherapy 7, 953-964.

Hemphill, A., Spicher, M., Stadelmann, B., Mueller, J., Naguleswaran, A., Gottstein, B. and Walker, $M$. (2007). Innovative chemotherapeutical treatment options for alveolar and cystic echinococcosis. Parasitology 134, 1657-1670.

Hemphill, A., Stettler, M., Walker, M., Siles-Lucas, M., Fink, R. and Gottstein, B. (2002). Culture of Echinococcus multilocularis metacestodes; an alternative to animal use. Trends in Parasitology 18, 445-449.

Holmes, E., Tsang, T. M., Huang, J. T., Leweke, F. M., Koethe, D., Gerth, C. W., Nolden, B. M., Gross, S., Schreiber, D., Nicholson, J. K. and Bahn, S. (2006). Metabolic profiling of CSF: evidence that early intervention may impact on disease progression and outcome in schizophrenia. PloS Medicine 3, e327. doi:10.1371/journal.pmed.0030327.

Horton, R. J. (1997). Albendazole in the treatment of human cystic echinococcosis: 12 years of experience. Acta Tropica 64, 79-93.

Hosch, W., Junghanss, T., Stojkovic, M., Brunetti, E., Heye, T., Kauffmann, G. W. and Hull, W. E. (2008). Metabolic viability assessment of cystic echinococcosis using high field ${ }^{1} \mathrm{H}$ MRS of cyst contents. NMR in Biomedicine 21, 734-754.

Hrckova, G. and Velebny, S. (1995). Effects of free and liposomized praziquantel on worm burden and antibody response in mice infected with Mesocestoides corti tetrathyridia. Fournal of Helminthology 69, 213-221.

Hrckova, G. and Velebny, S. (1997). Effect of praziquantel and liposome-incorporated praziquantel on peritoneal macrophage activation in mice infected with Mesocestoides corti tetrathyridia (Cestoda). Parasitology 114, 475-482.

Hrckova, G., Velebny, S. and Corba, J. (1998). Effects of free and liposomized praziquantel on the surface morphology and motility of Mesocestoides vogae tetrathyridia (syn. M. corti; Cestoda: Cyclophyllidea) in vitro. Parasitology Research 84, 230-238.

Hurd, H., Mackenzie, K. S. and Chappell, L. H. (1993). Anthelmintic effects of cyclosporin A on protoscoleces and secondary hydatid cysts of Echinococcus granulosus in the mouse. International Fournal for Parasitology 23, 315-320.

Ingold, K., Bigler, P., Thormann, W., Cavaliero, T., Gottstein, B. and Hemphill, A. (1999). Efficacies of albendazole sulfoxide and albendazole sulfone against in vitro cultivated Echinococcus multilocularis metacestodes. Antimicrobial Agents and Chemotherapy 43, 1052-1061.

Jain, M. K., Gupta, S., Katiyar, J. C., Maitra, S. C., Singh, J. and Bhakuni, D. S. (1989). Methyl 
5(6)-(alpha-hydroxyphenyl methyl) benzimidazole-2carbamate and cysticercosis: chemotherapeutic and electron microscopic studies. Indian Fournal of Experimental Biology 27, 454-459.

Jeziorski, M. C. and Greenberg, R. M. (2006). Voltage-cated calcium channel subunits from platyhelminths: potential role in praziquantel action. International fournal for Parasitology 36, 625-632.

Jura, H., Bader, A. and Frosch, M. (1998). In vitro activities of benzimidazoles against Echinococcus multilocularis metacestodes. Antimicrobial Agents and Chemotherapy 42, 1052-1056.

Jura, H., Bader, A., Hartmann, M., Maschek, H. and Frosch, M. (1996). Hepatic tissue culture model for study of host-parasite interactions in alveolar echinococcosis. Infection and Immunity 64, 3484-3490.

Kammerer, W. S. and Perez-Esandi, M. V. (1975). Chemotherapy of experimental Echinococcus granulosus infection. Trials in CF1 mice and jirds (Meriones unguiculatus). American fournal of Tropical Medicine and Hygiene 24, 90-95.

Keiser, J., Chollet, J., Xiao, S. H., Mei, J. Y., Jiao, P. Y., Utzinger, J. and Tanner, M. (2009). Mefloquine - an aminoalcohol with promising antischistosomal properties in mice. PLOS Neglected Tropical Diseases 3, $1-10$.

Keiser, J. and Utzinger, J. (2007a). Food-borne trematodiasis: current chemotherapy and advance with artemisinins and synthetic trioxolanes. Trends in Parasitology 23, 555-562.

Keiser, J. and Utzinger, J. (2007b). Artemisinins and synthetic trioxolanes in the treatment of helminthic infections. Current Opinions in Infectious Diseases 20 605-612.

Kern, P. (2003). Echinococcus granulosus infection: clinical presentation, medical treatment and outcome. Langenbecks Archives of Surgery 388, 413-420.

Kern, P. (2006). Medical treatment of echinococcosis under the guidance of Good Clinical Practice (GCP/ICH). Parasitology International 55 (Suppl.), S273-S282.

Kern, P., Abboud, P., Kern, W. V., Stich, A., Bresson-Hadni, S., Guerin, B., Buttenschoen, K., Gruener, B., Reuter, S. and Hemphill, A. (2008). Critical appraisal of nitazoxanide for the treatment of alveolar echinococcosis. American Fournal of Tropical Medicine and Hygiene 79, 119.

King, C. H. (2007). Lifting the burden of schistosomiasis - defining elements of infection-associated disease and the benefits of anti-parasite treatment. Fournal of Infectious Diseases 196, 653-655.

Kohn, A. B., Roberts-Misterly, J. M., Anderson, P. A. V., Khan, N. and Greenberg, R. M. (2003). Specific sites in the beta interaction domain of schistosome $\mathrm{Ca}^{2+}$ channel -subunit are key to its role in sensitivity to the anti-schistosomal drug praziquantel. Parasitology 127, 349-356.

Launchbury, A. P. and Habboubi, N. (1993). Epirubicin and doxorubicin: a comparison of their characteristics, therapeutic activity and toxicity. Cancer Treatment Reviews 19, 197-228.

Lawton, P., Hemphill, A., Deplazes, P., Gottstein, B., and Sarciron, M. E. (1997). Echinococcus multilocularis metacestodes : immunological and immunocytochemical analysis of the relationships between alkaline phosphatase and the Em2 antigen. Experimental Parasitology 87, 142-149.

Lawton, P., Walchshofer, N. and Sarciron, M. E. (2001). In vitro effects of isoprinosine and a dipeptide methyl ester on Echinococcus multilocularis protoscoleces. Fournal of Helminthology 75, 251-257.

Li, J. V., Wang, Y. L., Saric, J., Nicholson, J. K., Dirnhofer, S., Singer, B. H., Tanner, M., Wittlin, S., Holmes, E. and Utzinger, J. (2008). Gobal metabolic responses of NMRI mice to an experimental Plasmodium berghei infection. Fournal of Proteome Research 7, 3948-3956.

Liance, M., Bresson-Hadni, S., Vuitton, D. A., Lenys, D., Carbillet, J. P. and Houin, R. (1992). Effects of cyclosporin A on the course of murine alveolar echinococcosis and on specific cellular and humoral immune responses against Echinococcus multilocularis. International Fournal for Parasitology 22, 23-28.

Liance, M., Nemati, F., Bories, C. and Couvreur, P. (1993). Experience with doxorubicin-bound polyisohexylcyanoacrylate nanoparticles on murine alveolar echinococcosis of the liver. International Fournal for Parasitology 23, 427-429.

Maki, J. and Yanagisawa, T. (1985). Anthelmintic effects of bithionol, paromomycin sulphate, flubendazole and mebendazole on mature and immature Hymenolepis nana in mice. Fournal of Helminthology 59, 211-216.

Martin, F. P. J., Verdu, E. F., Wang, Y. L., Dumas, M. E., Yap, I. K. S., Cloarec, O., Bergonzelli, G. E., Corthesy-Theulaz, I., Kochhar, S., Holmes, E., Lindon, J. C., Collins, S. M. and Nicholson, J. K. (2006). Transgenomic interactions in a mouse disease model: interaction of Trichinella spiralis infection with dietary Lactobacillus paracasei supplementation. Fournal of Proteome Research 5, 2185-2193.

Martinez, J., Perez-Serrano, J., Bernadina, W. E. and Rodriguez-Caabeiro, F. (1999). Echinococcus granulosus: in vivo effects of ivermectin and praziquantel on hsp60 and hsp70 levels. Experimental Parasitology 93, 171-180.

Martinez Zedillo, G., Hoyo Badillo, C., Amezcua, J. and Gonzalez Barranco, D. (1992). Verapamil does not block the spastic response of praziquantel on the larvae of Taenia pisiformis. Archives of Medical Research 23, 73-77.

Marchiondo, A. A., Ming, R., Andersen, F. L., Slusser, J. H. and Conder, G. A. (1994). Enhanced larval cyst growth of Echinococcus multilocularis in praziquantel-treated jirds (Meriones unguiculatus). American Fournal of Tropical Medicine and Hygiene 50, 120-127.

Mathis, A., Wild, P., Boettger, E. C., Kapel, C. M. O. and Deplazes, P. (2005). Mitochondrial ribosome as the target for the macrolide antibiotic clarithromycin in the helminth Echinococus multilocularis . Antimicrobial Agents and Chemotherapy 49, 3251-3255.

Matsumoto, J., Müller, N., Hemphill, A., Oku, Y., Kamiya, M. and Gottstein, B. (2006). 14-3-3- and II/3-10 gene expression as molecular markers to address viability and growth activity of Echinococcus multilocularis metacestodes. Parasitology 392, 98-105. 
Matsumoto, J., Sakamoto, K., Shiniyo, N., Kido, Y., Yamamoto, N., Yagi, K., Miyoshi, H., Nonaka, N., Katakura, K., Kita, K. and Oku, Y. (2008). Anaerobic $\mathrm{NADH}$-fumarate reductase system is predominant in the respiratory chain of Echinococcus multilocularis providing a novel target for the chemotherapy of alveolar echinococcosis. Antimicrobial Agents and Chemotherapy 52, 164-170.

McManus, D. P., Wenbao, Z., Jun, L. and Bartley, P. B. (2003). Echinococcosis. The Lancet 362, 1295-1304.

McTigue, M. A., Williams, D. R. and Tainer, J. A. (1995). Crystal structures of a schistosomal drug and vaccine target: glutathione S-transferase from Schistosoma japonica and its complex with the leading anti-schistosomal drug praziquantel. Fournal of Molecular Biology 246, 21-27.

Mehlhorn, H., Eckert, J. and Thompson, R. C. A. (1983). Proliferation and metastases formation of larval Echinococcus multilocularis II. Ultrastructural investigations. Zeitschrift für Parasitenkunde 69, 749-763.

Miyaji, S., Katakura, K., Matsufuji, S., Murakami, Y., Hayashi, S., Oku, Y., Okamoto, M. and Kamiya, M. (1993). Failure of treatment with alphadifluoromethylornithine against secondary multilocular echinococcosis in mice. Parasitology Research 79, 75-76.

Moreno, M. J., Casado, N., Urrea-París, M. A. and Rodríguez-Caabeiro, F. (2002). Could ivermectin have a synergic effect with albendazole in hydatidosis therapy? Parasitology Research 88, 563-567.

Morris, D. L., Chinnery, J. B. and Ubhi, C. (1987). A comparison of the effects of albendazole, its sulphone metabolite, and mebendazole on the viability of protoscoleces of Echinococcus granulosus in an in vitro culture system. Transactions of the Royal Society of Tropical Medicine and Hygiene 81, 804-806.

Morris, D. L., Richards, K. S. and Chinnery, J. B. (1986). Protoscolicidal action of praziquantel - in vitro and electron microscopical studies on Echinococcus granulosus. Fournal of Antimicrobial Chemotherapy 18, 687-691.

Morseth, D. J. (1967). Fine structure of the hydatid cyst and protoscolex of Echinococcus granulosus. Fournal of Parasitology 53, 312-325.

Müller, J., Naguleswaran, A., Müller, N. and Hemphill, A. (2008a). Neospora caninum: functional inhibition of protein disulfide isomerase by the broad-spectrum anti-parasitic drug nitazoxanide and other thiazolides. Experimental Parasitology 118, 80-88.

Müller, J., Sidler, D., Nachbur, U., Wastling, J., Brunner, T. and Hemphill, A. (2008b). Thiazolides inhibit growth and induce glutathione-S-transferase $\mathrm{Pi}$ (GSTP1)-dependent cell death in human colon cancer cells. International Fournal of Cancer 123, 1797-1806.

Naguleswaran, A., Spicher, M., Vonlaufen, N., Ortega-Mora, L. M., Torgerson, P., Gottstein, B. and Hemphill, A. (2006). In vitro metacestodicidal activities of genistein and other isoflavones against Echinococcus multilocularis and Echinococcus granulosus. Antimicrobial Agents and Chemotherapy 50, 3770-3778.

Nakao, M., McManus, D. P., Schantz, P. M., Craig, P. S. and Ito, A. (2007) A molecular phylogeny of the genus Echinococcus inferred from complete mitochondrial genomes. Parasitology 134, 713-722.

Nessim, N. G., Hassan, S. I., William, S. and El-Baz, H. (2000). Efffect of the broad spectrum antheminthic drug flubenadazole upon Schistosoma mansoni experimentally infected mice. Arztneimittelforschung 50, 1129-1133.

Nogi, T., Zhang, D., Chan, J. D., and Marchant, J. S. (2009). A novel bological activity of praziqunatel requiring voltage-operated $\mathrm{Ca}^{2+}$ channel beta subunits : subversion of flatworm regenerative polarity. PloS Neglected Tropical Diseases 3, e464.

Novak, M. and Blackburn, B. J. (1985). Comparison of the effects of imidazo[1,2-a]pyridine-2-carbamates and benzimidazole-2-carbamates on the development of Hymenolepis nana in Tribolium confusum. Experientia 41, 687-689.

Ochieng'-Mitula, P. J. and Burt, M. D. (1996). The effects of ivermectin on the hydatid cyst of Echinococcus granulosus after direct injection at laparotomy. Fournal of Parasitology 82, 155-157.

Ordovas, J. M. and Mooser, V. (2006). Metagenomics: the role of the microbiome in cardivascular diseases. Current Opinion in Lipidology 17, 157-161.

Palomares-Alonso, F., Piliado, J. C., Palencia, G., Ortiz-Plata, A. and Jung-Cook, H. (2007). Efficacy of nitazoxanide, tizoxanide, and tizoxanide/albendazole sulphoxide combination against Taenia crassiceps cysts. Fournal of Antimicrobial Chemotherapy 59, 212-218.

Perez Serrano, J., Casado, N., Guillermo, Denegri, Rodriguez-Caabeiro, F. (1994). The effects of albendazole and albendazole sulphoxide combination-therapy on Echinococcus granulosus in vitro. International Fournal for Parasitology 24, 219-224.

Rausch, R. L. (1995). Life cycle patterns and geographic distribution of Echinococcus species. In Echinococcosis and Hydatid Disease (ed. Thompson, R. C. A. and Lymbery, A. J.), pp. 89-99. Wallmingford: CAB International.

Reuter, S., Buck, A., Grebe, O., Nüssle-Kügele, K., Kern, P. and Manfras, B. (2003b). Salvage treatment with amphotericin B in progressive human alveolar echinococcosis. Antimicrobial Agents and Chemotherapy 47, 3586-3591.

Reuter, S., Buck, A., Manfras, B., Kratzer, W., Seitz, H. M., Darge, K., Reske, S. N. and Kern, P. (2004). Structured treatment interuption in patients with alveolar echinococcosis. Hepatology 39, 509-517.

Reuter, S., Jensen, B., Buttenschoen, K., Kratzer, W. and Kern, P. (2000). Benzimidazoles in the treatment of alveolar echinococcosis. Fournal of Antimicrobial Chemotherapy 46, 451-460.

Reuter, S., Manfras, B., Merkle, M., Harter, G. and Kern, P. (2006). In vitro activities of itraconazole, methiazole, and nitazoxanide versus Echinococcus multilocularis larvae. Antimicrobial Agents and Chemotherapy 50, 2966-2970.

Reuter, S., Merkle, M., Brehm, K., Kern, P. and Manfras, B. (2003a). Effect of amphotericin B on larval growth of Echinococcus multilocularis. Antimicrobial Agents and Chemotherapy 47, 620-625.

Robinson, M. W., Hoev, E. M., Fairweather, I., Dalton, J. P., McGonigle, S. and Trudgett, A. (2001). Characterization of a beta tubulin gene from the liver 
fluke Fasciola hepatica. International Fournal for

Parasitology 31, 1264-1268.

Rodriguez-Caabeiro, F., Casado, N. and Juarez-Pelaez, E. (1989). Efecto in vitro de praziquantel, mebendazole y oxfendazole sobre protoscolex de Echinococcus granulosus. Revista Iberica Parasitologica 49, 77-83.

Rogan, M. T. and Richards, K. S. (1986). Echinococcus granulosus: in vivo effect of monensin on the tegument of the protoscolex. Parasitology 93, 347-355.

Saldana, J., Marin, M., Fernandez, C. and Dominguez, L. (2001). In vitro taurocholate-induced segmentation and clustering of Mesocestoides vogae (syn. corti) tetrathyridia (Cestoda) - inhibition by cestocidal drugs. Parasitology Research 87, 281-286.

Sarciron, E. M., Bresson-Hadni, S., Mercier, M., Lawton, P., Duranton, C., Lenys, D., Petavy, A. F. and Vuitton, D. A. (1997). Antibodies against Echinococcus multi locularis phosphatase as markers for the specific diagnosis and the serological monitoring of alveolar echinococcosis. Parasite Immunology 19, 61-68.

Sarciron, M. E., Hamoud, W., Azzar, G., and Petavy, A. F. (1991). Alkaline phosphatase from Echinococcus multilocularis: purification and characterization. Compendium of Biochemistry and Physiology 100, 253-258.

Saric, J., Li, J. V., Wang, Y., Keiser, J., Bundy, J. G., Holmes, E. and Utzinger, J. (2008). Metabolic profiling of an Echinostoma caproni infection in the mouse for biomarker discovery. PloS Neglected Tropcial Diseases 2, e254. doi: 10.1371/journal.pntd.0000254

Schantz, P. M., Chai, J., Craig, P. S., Eckert, J., Jenkins, D. J., Macpherson, C. N. L. and Thakur, A. (1995). Epidemiology and control of hydatid disease. In Echinococcosis and Hydatid Disease (ed. Thompson, R. C. A. and Lymbery, A. J.), pp. 233-245.

Wallmingford: CAB International.

Schipper, H. G., Koopmans, R. P., Nagy, J., Butter, J. J., Kaeger, P. A. and Van Boxtel, C. J. (2000). Effect of dose increase or cimetidine co-administration on albendazole bioavailability. American fournal of Trpocial Medicine and Hygiene 63, 270-273.

Schmidt, J. (1998). Effects of benzimidazole antheminthics as microtubule-active drugs on the synthesis of surface glycoconjugates in Echinostoma caproni, Hymenolepis microstoma and Schistosoma mansoni. Parasitology Research 84, 362-368.

Schumacher, G. and Neuhaus, P. (2001). The physiological estrogen metabolite 2-methoxyestradiol reduces tunor growth and induces apoptosis in human solid tunors. Fournal of Cancer Research and Clinical Oncology 127, 405-410.

Shandera, W. X. and Kass, J. S. (2006).

Neurocysticercosis: current knowledge and advances.

Current Neurology and Neuroscience Reports 6, 453-459.

Siles-Lucas, M. and Hemphill, A. (2002). Cestode parasites: Application of in vivo and in vivo models for studies on the host-parasite relationship. Advances in Parasitology 51, 133-230.

Spicher, M., Naguleswaran, A., Ortega-Mora, L. M., Mueller, J., Gottstein, B. and Hemphill, A. (2008a). In vitro and in vivo effects of 2-methoxyestradiol, either alone, or combined with albendazole, against Echinococcus metacestodes. Experimental Parasitology 119, 475-482.
Spicher, M., Roethlisberger, C., Lany, C., Stadelmann, B., Keiser, J., Ortega-Mora, L. M., Gottstein, B. and Hemphill, A. (2008b). In vitro and in vivo treatments of Echinococcus protoscoleces and metacestodes with artemisinin derivatives. Antimicrobial Agents and Chemotherapy 52, 3447-3450.

Spiliotis, M. and Brehm, K. (2008). Axenic in vitro cultivation of Echinococcus multilocularis metacestode vesicles and the generation of primary cell cultures. In Host Pathogen Interactions (ed. Rupp, S. and Sohn, K.), pp. 245-262. Humana Press.

Spiliotis, M., Lechner, S., Tappe, D., Scheller, D., Krohne, G. and Brehm, K. (2008). Transient tranfection of Echinococcus multilocularis primary cells and complete in vitro regeneration of metacestode vesicles. International Fournal for Parasitology 38, 1025-1039.

Spiliotis, M., Tappe, D., Sesterhenn, L. and Brehm, K. (2004). Long-term in vitro cultivation of Echinococcus multilocularis metacestodes under axenic conditions. Parasitology Research 92, 430-432.

Stettler, M., Fink, R., Walker, M., Gottstein, B., Geary, T. G., Rossignol, J. F. and Hemphill, A. (2003). In vivo parasiticidal effect of nitazoxanide against Echinococcus multilocularis metacestodes. Antimicrobial Agents and Chemotherapy 47, 467-474.

Stettler, M., Rossignol, J. F., Fink, R., Walker, M., Gottstein, B., Merli, M., Theurillat, R., Thormann, W., Dricot, E., Segers, R. and Hemphill, A. (2004). Secondary and primary murine alveolar echinococcosis : combined albendazole/nitazoxanide chemotherapy exhibits profound anti-parasitic activity. International Fournal for Parasitology 34, 615-624.

Stettler, M., Siles-Lucas, M., Sarciron, E., Lawton, P., Gottstein, B. and Hemphill, A. (2001). Echinococcus multilocularis alkaline phosphatase as a marker for metacestode damage induced by in vitro drug treatment with albendazole sulphoxide and albendazole sulfone. Antimicrobial Agents and Chemotherapy 45, 2256-2262.

Stey, C. and Jost, R. (1993). Rezidivierende, lebensbedroliche Anaphylaxie als Erstmanifestation eines Echinococcus cysticus (granulosus) der Leber. Schweizerische Medizinische Wochenzeitschrift 123, 1445-1450.

Tallima, H. and E1 Ridi, R. (2007). Praziquantel binds Schistosoma mansoni adult worm actin. International Fournal of Antimicrobial Agents 29, 570-575.

Taylor, D. H. and Morris, D. L. (1988). In vitro culture of Echinococcus multilocularis: protoscolicidal action of praziquantel and albendazole sulphoxide. Transactions of the Royal Society of Tropical Medicine and Hygiene 82, 265-267.

Taylor, D. H., Richards, K. S. and Morris, D. L. (1989). Rapid recovery of Echinococcus granulosus following 'successful' albendazole therapy in a gerbil model. Fournal of Helminthology 63, 349-352.

Tellez-Giron, E., Ramos, M. C. and Montante, M. (1981). Effect of flubendazole on Cysticercus cellulosae in pigs. American Fournal of Tropical Medicine and Hygiene 30, 135-138.

Tellez-Giron, E., Ramos, M. C., Dufour, L., Montante, M., Tellez, E., Jr. Rodriguez, J., Gomez-Mendez, F. and Mireles, E. (1984). 
Treatment of neurocysticercosis with flubendazole. American Fournal of Tropical Medicine and Hygiene 33, 627-631.

Terenina, N. V., Kosovatova, L. A., Gerasimova, E. I. and Shalaeva, N. M. (1998). The effect of anthelmintics on the serotonin content of cestodes. Meditsinskaia parazitologiia i parazitarnye bolezni $\mathbf{1}$, 10-15.

Thompson, R. C. A. (1986). Biology and systematics of Echinococcus. In The Biology of Echinococcus and Hydatid Disease (ed. Thompson, R. C. A.), pp. 5-17. Allen \& Unwin, London.

Urrea-Paris, M. A., Casado, N., Moreno, M. J. and Rodriguez-Caabeiro, F. (2001). Chemoprophylactic praziquantel treatment in experimental hydatidosis. Parasitology Research 87, 510-512.

Urrea-Paris, M. A., Moreno, M. J., Casado, N. and Rodriguez-Caabeiro, F. (1999). Echinococcus granulosus: praziquantel treatment against the metacestode stage. Parasitology Research 85, 999-1006.

Utzinger, J., Chollet, J., Tu, Z., Xiao, S. and Tanner, M. (2002). Comparative study of the effects of artemether and artesunate on juvenile and adult Schistosoma mansoni in experimentally infected mice. Transactions of the Royal Society of Tropical Medicine and Hygiene 96, 318-323.

Varcasia, A., Garippa, G., Pipia, A. P., Scala, A., Brianti, E., Giannetto, S., Battelli, G., Poglayen, G. and Micagni, G. (2008) Cystic echinococcosis in equids in Italy. Parasitology Research 102, 815-818.

Verheyen, A., Vanparijs, O., Borgers, M. and Thienpont, D. (1978). Scanning electron microscopic observations of Cysticercus fasciolaris (= Taenia taeniaeformis) after treatment of mice with mebendazole. Fournal of Parasitology 64, 411-425.

Voelker, R. (2009). Attention sought for negelected diseases. Fournal of the American Medical Association 301, 1755-1756.

Vuitton, D. (2009). Benzimidazoles for the treatment of cystic and alveolar echinococcosis: what is the consensus? Expert Review in Anti-Infective Therapy 7, 145-149.

Vutova, K., Mechkov, G., Vachkov, P., Petkov, R., Georgiev, P., Handjiev, S., Ivanov, A. and Todorov, T. (1999). Effect of mebendazole on human cystic echinococcosis : the role of dosage and treatment duration. Annals of Tropical Medicine and Parasitology 93, 357-365.

Walker, M., Rossignol, J. F., Torgerson, P. and

Hemphill, A. (2004). In vivo effects of nitazoxanide on Echinococcus granulosus protoscoleces and metacestodes. Fournal of Antimicrobial Chemotherapy 54, 609-616.

Wang, Y. L., Holmes, E., Nicholson, J. K., Cloarec, O., Chollet, J., Tanner, M., Singer, B. H. and Utzinger, J. (2004). Metabolomic investigations in mice infected with Schistosoma mansoni: an approach for biomarker identification. Proceedings of the National Academy of Sciences, USA 101, 12676-12681.

Wang, Y. L., Utzinger, J., Saric, J., Li, J. V., Burckhardt, J., Dirnhofer, S., Nicholson, J. K., Singer, B. H., Brun, R. and Holmes, E. (2008). Global metabolic responses of mice to Trypanosoma brucei brucei infection. Proceedings of the National Academy of Sciences, USA 105, 6127-6132.

Wang, Y. L., Utzinger, J., Xiao, S. H., Xue, J., Nicholson, J. K., Tanner, M., Singer, B. H. and Holmes, E. (2006). System level metabolic effects of a Schistosoma japonicum infection in the Syrian hamster. Molecular and Biochemical Parasitology 146, $1-9$.

Wen, H., New, R. R., Muhmut, M., Wang, J. H., Wang, Y. H., Zhang, J. H., Shao, Y. M. and Craig, P. S. (1996). Pharmacology and efficacy of liposome-entrapped albendazole in experimental secondary alveolar echinococcosis and effect of co-administration with cimetidine. Parasitology 113, 111-121.

Wiest, P. M., Li, Y., Olds, R. and Bowen, W. D. (1992). Inhibition of phosphoinositide turnover by praziquantel in Schistosoma mansoni. Fournal of Parasitology 78, 753-755.

Williams, S., Guirgus, F. and Nessim, N. G. (2003). Effect of simultaneous and/or consective administration of the broad spectrum anthelminthic flubendazole together with praziquantel in experimental Schistosoma mansoni infection. Arztneimittelforschung 53, 532-537.

Winning, A., Braslins, P. and McCarthy, J. S. (2009). Case report: nitazoxanide for the treatment of refractory bony hydatid disease. American Fournal of Tropical Medicne and Hygiene 80, 176-178. 